\title{
The Role of Dietary Phenolic Compounds in Protein Digestion and Processing Technologies to Improve Their Antinutritive Properties
}

\author{
Tanja D. Cirkovic Velickovic (iD) and Dragana J. Stanic-Vucinic
}

\begin{abstract}
Digestion is the key step for delivering nutrients and bioactive substances to the body. The way different food components interact with each other and with digestive enzymes can modify the digestion process and affect human health. Understanding how food components interact during digestion is essential for the rational design of functional food products. Plant polyphenols have gained much attention for the bioactive roles they play in the human body. However, their strong beneficial effects on human health have also been associated with a negative impact on the digestion process. Due to the generally low absorption of phenolic compounds after food intake, most of the consumed polyphenols remain in the gastrointestinal tract, where they then can exert inhibitory effects on enzymes involved in the degradation of saccharides, lipids, and proteins. While the inhibitory effects of phenolics on the digestion of energy-rich food components (saccharides and lipids) may be regarded as beneficial, primarily in weight-control diets, their inhibitory effects on the digestion of proteins are not desirable for the reason of reduced utilization of amino acids. The effect of polyphenols on protein digestion is reviewed in this article, with an emphasis on food processing methods to improve the antinutritive properties of polyphenols.
\end{abstract}

Keywords: digestion, flavonoid, polyphenol, protein, tannin

\section{Introduction}

Plant secondary metabolites are formed inside specialized plant cells and one of their main roles are protection and signaling (Ignat and others 2011). The major group of plant secondary metabolites is polyphenols, which include compounds of diverse structures, molecular weights, and properties, and are ubiquitously present in plant-based foods such as tea, coffee, wine, cocoa, cereal grains, soy, fruits, and berries (Tsao 2010).

Polyphenol compounds were originally known as "vegetable tannins" due to their ability to interact with proteins of the skin in the process of tanning that transforms animal skins into leather. Their usefulness in the transformation of animal skins into leather (Quideau and others 2011) was discovered as far back as 800 to $500 \mathrm{BC}$ by the ancient Greeks, who used oak galls in skin processing. Tanning occurs because of the hydrogen bonding of a large number of phenolic groups in the polyphenols of skin collagen.

CRF3-2017-0151 Submitted 7/21/2017, Accepted 10/18/2017. Author Cirkovic Velickovic is with the Ghent Univ. Global Campus, 119 SongdomunhwaRo, Yeonsu-Gu, Incheon 21985, Korea. Author Cirkovic Velickovic is with Faculty of Bioscience Engineering, Ghent Univ., Coupure Links 653, 9000 Ghent, Belgium. Authors Cirkovic Velickovic and Stanic-Vucinic are with Center of Excellence for Molecular Food Sciences, Faculty of Chemistry, Univ. of Belgrade, Studenstki tro 16, 11000 Belgrade, Serbia. Direct inquiries to author Cirkovic Velickovic (E-mail: tanja.velickovic@ghent.ac.kr).
All vegetable tannins are polyphenols, but not all polyphenols have tanning capacity. The term "tannin" should only be used in reference to plant polyphenolic materials having molecular masses between 500 and $3000 \mathrm{Da}$ and the ability to form hydrogenbonded cross-linked structures with collagen that result in tanning. Gallic acids, like many simple polyphenols, cannot form cross-links with collagen nor be used in the tanning process.

The capacity of plant phenolics to exert a tanning action on skin collagen molecules is not essential to qualify them as polyphenols, although a precipitation reaction with soluble proteins is required. This very strict definition of polyphenols recognizes only 3 classes of compounds as "true" polyphenols: the proanthocyanidins (condensed tannins), the gallo- and ellagitannins (hydrolyzable tannins), and the phlorotannins (Haslam and Cai 1994). Because many traditional polyphenols such as poly (hydroxyphenylpropanoid)-based lignin polymers do not meet this strict definition, a revised definition was recently proposed based on the chemical properties and biosynthetic origin of plant secondary metabolites:

In organic chemistry, a class of chemical compounds containing a hydroxyl group $(-\mathrm{OH})$ directly bonded to an aromatic hydrocarbon group is known as phenols or phenolics. For the true plant polyphenols the term "polyphenol" should be used to define plant secondary metabolites derived exclusively from the shikimate-derived phenylpropanoid and/or the polyketide pathway(s), featuring more than one phenolic ring and being devoid of any nitrogen-based functional group in their most basic structural expression (Quideau and others 2011). However, from a chemical 
point of view polyphenols are a structural class of natural, semisynthetic or synthetic organic compounds characterized by the presence of multiple phenolic moieties.

This definition leaves out all monophenolic structures such as vanillin, salicylic acid, hydroxytyrosol, gallic acid, catechol, resorcinol, caffeic acid, pyrogallol, and phloroglucinol, as well as all the naturally occurring derivatives such as methyl phenyl ethers and $\mathrm{O}$-phenyl glycosides. However, their role as precursors in the biosynthesis of polyphenols and their various biological activities, which resemble those of polyphenols, make them an important subject of research. Therefore, throughout this review we will focus on both polyphenols and monophenolic compounds and their impact on the digestion of proteins.

\section{Structural Features of Plant Phenolic Compounds}

Phenolic acids are therefore important phenolic compounds that, strictly speaking, are not polyphenols. Their structures are of the C6 to C1 (benzoic acid derivative) or C6 to C3 (cinnamic acid derivative) types, and the most important examples are caffeic acid, gallic acid, ferulic acid, and p-coumaric acid (Kroll and others 2003).

Flavonoids are polyphenols with the C6-C3-C6 general backbone structure in which the two C6 units (Ring A and Ring B) are of a phenolic nature (Tsao 2010). Due to the hydroxylation pattern and variations in the chromane ring (Ring C), flavonoids can be further divided into different subgroups, such as flavans, flavanones, isoflavanones, flavones, isoflavones, anthocyanidins, chalcones, and flavonolignans (Tsao 2010).

The basic structure of polyphenols may undergo oligomerization, giving rise to higher-molecular-weight compounds, commonly known as "true" vegetable tannins. These include: (1) the proanthocyanidins (condensed tannins) such as procyanidins, prodelphinidins, and profisetinidins, which are produced by the oligomerization of flavan-3-ol units such as (epi)catechin, epigallocatechin, and fisetinidol; (2) the gallo- and ellagitannins (hydrolyzable tannins), which are derived from the metabolism of the shikimate-derived gallic acid that leads through esterification and phenolic oxidative coupling reactions to numerous (close to 1000) monomeric and oligomeric polyphenolic galloyl ester derivatives of sugar-type polyols, mainly D-glucose; and (3) the phlorotannins that are found in red-brown algae and are essentially derived from the oligomerizing dehydrogenative coupling of phloroglucinol (Quideau and others 2011).

The isolation, identification, and further development of phenolic compounds or extracts from plants have become an important area of health and biomedical research. Dai and Mumper (2010) authored a comprehensive review on plant phenolic extraction, purification, analysis, and quantification and the antioxidant properties of polyphenols (Dai and Mumper 2010). Due to the structural diversity of the group, a standard extraction method for the isolation of polyphenols does not exist. Solvent extraction (liquid-liquid extraction or solid-liquid extraction) and extraction with supercritical fluids are the most commonly used techniques for the isolation of phenolic compounds (Ignat and others 2011). The most common solvent extraction methods are those using acidified methanol or ethanol (Tsao 2010; Ignat and others 2011).

\section{Health Effects of Plant Phenolic Compounds}

Due to their structure consisting of a highly conjugated system with numerous hydroxyl groups, and particularly the presence of hydroxylation patterns such as the 3-hydroxy group in flavonols, polyphenols are an important part of the plant defense systems against oxidative stress and UV radiation.

Their antioxidative properties have been linked to their numerous beneficial effects on human health (Pandey and Rizvi 2009). It is widely believed that consumption of a variety of phenolic compounds present in foods and beverages may lower the risk of health disorders because of their antioxidant activity (Shahidi and Ambigaipalan 2015). Polyphenols neutralize free radicals by donating an electron or hydrogen atom due to their highly conjugated system and hydroxylation patterns, such as the 3-hydroxy group in flavonols. Polyphenols reduce the rate of oxidation by suppressing the generation of free radicals, or by deactivation of the reactive species and precursors of free radicals. They act as direct radical scavengers of the lipid peroxidation chain reactions by donating an electron to free radicals, resulting in radical neutralization, while they become less reactive radicals, thus stopping the chain reactions (Tsao 2010). However, there are evidences indicating that only slight portion of consumed polyphenol compounds reaches human plasma (Clifford 2004). Since plasma total antioxidant capacities are often in the range of $1 \mathrm{mM}$, and plasma levels of unconjugated flavonoids rarely exceed $1 \mu \mathrm{M}$, this fraction makes insignificant contribution to the total antioxidant activity of plasma (Halliwell 2007). This suggests that free radical scavenging is not likely to be mechanism by which diets rich in phenolic compounds protect against chronic desesses (Clifford 2004).

Besides their antioxidative activity, the ability of polyphenols, especially vegetable tannins, to interact with dietary proteins deserves particular attention, as some of these interactions may have detrimental effects on human and animal welfare and health.

In solution, polyphenols can form noncovalent complexes with globular proteins, and such interactions may result in complexation (Li and others 2010; Chaudhuri and others 2011), stabilization of protein structure (Kanakis and others 2011), protein unfolding, and precipitation (Siebert and others 1996; Papadopoulou and Frazier 2004; Ehrnhoefer and others 2008; Ma and others 2011). The strength of the interactions depends on the size of the polyphenols, the polyphenol structure, and the amino acid sequence of the proteins (Frazier and others 2010). In basic conditions, covalent bonds between proteins and polyphenols are readily formed. The chemistry of protein-polyphenol interactions has been recently reviewed (Czubinski and Dwiecki 2017).

Many polyphenols occur in nature as glycosylated derivatives. In order to become bioactive in the human body, polyphenols must undergo numerous intestinal transformations, which occur due to the action of digestive enzymes, but also by the action of microbiota metabolism (Karaś and others 2017). The final absorbed compounds enter the portal vein circulation toward the liver, where further enzymatic transformations take place, and from there to other organs, or via blood toward urine excretion. During this transit through various tissues and organs, they are able to exert their biological activities (Wang and others 2014; Marín and others 2015).

Isoflavones are the most well-absorbed polyphenols, followed by catechins, flavanones, and quercetin glucosides, but with different kinetics. The least well-absorbed polyphenols are the proanthocyanidins, the galloylated tea catechins, and the anthocyanins (Manach and others 2005). The most recent investigations on the bioavailability of anthocyanins and flavanones suggest that they could be more bioavailable than previously thought (Kay and others 2017). Data also show that protein-rich diets do not influence the uptake, distribution, and excretion of phenols (Draijer and others 2016). 
The ability of polyphenolic compounds to form insoluble complexes has been associated with the observed reduction in nutritive value resulting from their inclusion in animal diets. Due to the generally low absorption of polyphenols after food intake, most of the consumed polyphenols remain in the gastrointestinal tract (GIT), where they may influence the activity of digestive enzymes (Karaś and others 2017; Renard and others 2017). Polyphenol compounds have been found to inhibit crucial enzymes involved in starch and lipid digestion, such as $\alpha$-amylase, $\alpha$-glucosidase, and pancreatic lipase (Boath and others 2012; Sakulnarmrat and others 2014; Lochocka and others 2015), as well as protein digestion, such as pepsin and trypsin (He and others 2007).

While the inhibitory effects of phenolics on the digestion of energy-rich food components (saccharides and lipids) can be regarded as beneficial, primarily in weight-control diets, their inhibitory effects on the digestion of proteins are not desirable because of the reduction in utilization of valuable building blocks (amino acids).

This review provides an overview of the published data on the effects of polyphenols on digestive enzyme activity and protein digestion, and on food-processing methods that can improve the antinutritive properties of polyphenol-rich foods.

\section{Protein digestibility is mainly determined by phenolic compounds influence on protease activity and protein substrate accessibility}

The effects of phenolic compounds on protein digestibility are consequences of their binding to endogenous proteins, mainly digestive proteases, as well as protein substrates. In that way phenolic compounds binding influence protease activity and protein substrate accessibility, which are the key factors influencing protein digestibility.

The binding of phenolic compounds to proteases can have various effect: inhibition, as demonstrated in most of the studies, activation, or no effect at all. It seems that effect of phenolic compounds on enzyme activity is positively correlated with their binding affinity to enzyme. As the enzymes are proteins themselves, their amino acid composition, molecular size, as well as their structure are the main determinants of enzyme affinity to phenolic compounds. In general, phenolic compound binding could loosen or stabilize enzyme structure, and in that way may change enzyme activity. Disturbing of protein structure can be expected particularly in the case of phenolics with bulky structure, such as tannins, or glycosides of phenolic compounds. The loosening of enzyme structure can, on one hand, destabilize enzyme conformation and proper position/orientation of substrate binding/catalytic residues, resulting in enzyme inhibition, and, on the other hand can allow better fitting of protein substrate, resulting in enzyme activation. Also phenolic compounds may act as allosteric regulators of enzyme activity. Beside, phenolic compound binding can hinder substrate binding site, catalytic site or both, therefore reducing its proteolytic activity. There is also opinion that majority of reported polyphenol-enzyme interactions lead to enzyme inhibition via allosteric denaturing rather than single site inhibition, where multiple allosteric binding induce conformational changes and cause loss of the active conformation.

Similarly to proteases, polyphenolic compounds could stabilize or destabilize protein substrate structure, therefore making them less or more prone to proteolytic attack. This can be especially important for protein digestibility by pepsin, which is highly depending on protein substrate flexibility at low $\mathrm{pH}$. Again, binding of a phenolic compound can reduce the accessibility of protein substrate to enzyme. The protein binding of phenols, mainly interacting with hydrophobic sites on the protein, can particularly reduce the accessibility to proteases with preference for hydrophobic residues. It has to be mentioned that if, for example, phenolic compound binding destabilize protein structure inducing its partial unfolding, and in that way increasing its accessibility to enzyme, and, at the same time hinders some of sites of enzyme action, the result would be increased disappearance of intact protein, but released peptides would be longer and resistant to further proteolysis. Here we come to the question should we regard this as real increased digestibility or not. Unfortunately, the most of the studies monitor disappearance of intact (or truncated) protein, or quantity of whole peptide fraction soluble in for example, trichloroacetic acid (TCA), without analyzing if these peptides are actually longer in the samples with bound phenolic compounds. Therefore, protein digestibility depends on net result of extent of both enzyme and protein substrate structure stabilization or destabilization, and both enzyme and protein substrate shielding by phenolic compound binding, noncovalent or covalent.

In general, as phenol compounds can influence protein hydrolysis by their interactions with protein substrate, as well as protease itself, it is hard to resolute net effect of phenolic compounds of protease activity using protein substrate, even standardly used protein such as hemoglobin or azocasein. Therefore, the only reliable way to distinguish net effects on protease activity itself is monitoring protease activity using small synthetic substrate, whose availability to substrate binding/catalytic site of enzyme is not influenced by the presence of phenolic compounds. Unfortunately, almost all studies have used protein substrates for investigation of effects of phenolic compounds on protease activity, and, depending on substrate used, obtained different effect and extent of polyphenol compound influence.

\section{Effects of binding of phenolic compounds to endogenous proteins (digestive enzymes and proteins of saliva and gastrointestinal mucus)}

The influence of phenolic compound on protein digestibility is the consequence of phenolics binding to dietary proteins on one hand and their binding to endogenous proteins, such as digestive enzymes, proteins of saliva, gastric and intestinal mucus, and other endogenous proteins on the luminal side of the intestinal tract.

\section{Effects of phenolic compounds on the activity of digestive proteases}

In general, a polyphenolic compound exhibiting strong complexing abilities with proteins could alter enzyme structures and lead to the loss of catalytic activity. It has been reported in several studies that phenolic compounds influence the activity of many enzymes, as observed by changes in the kinetic parameters. Of the digestive proteases, the most frequently studied are pepsin (an acidic protease of the upper GIT), and trypsin, chymotrypsin, and elastase (serine proteases active at higher $\mathrm{pH}$ and residing in the duodenum).

Effects of phenolic compounds on pepsin activity. A review of the literature on the effect of plant phenolic compounds on pepsin activity reveals conflicting evidence (Table 1). It can be observed that all listed studies conducted pepsin activity determination under different conditions, with different substrates, using different assessment methods. Moreover, even within the same study, for example in the study of Tagliazucchi and others (2005), pepsin activity on different substrates was done under different conditions, such as phenolics/pepsin ratio, digestion time, phenolics/substrate 


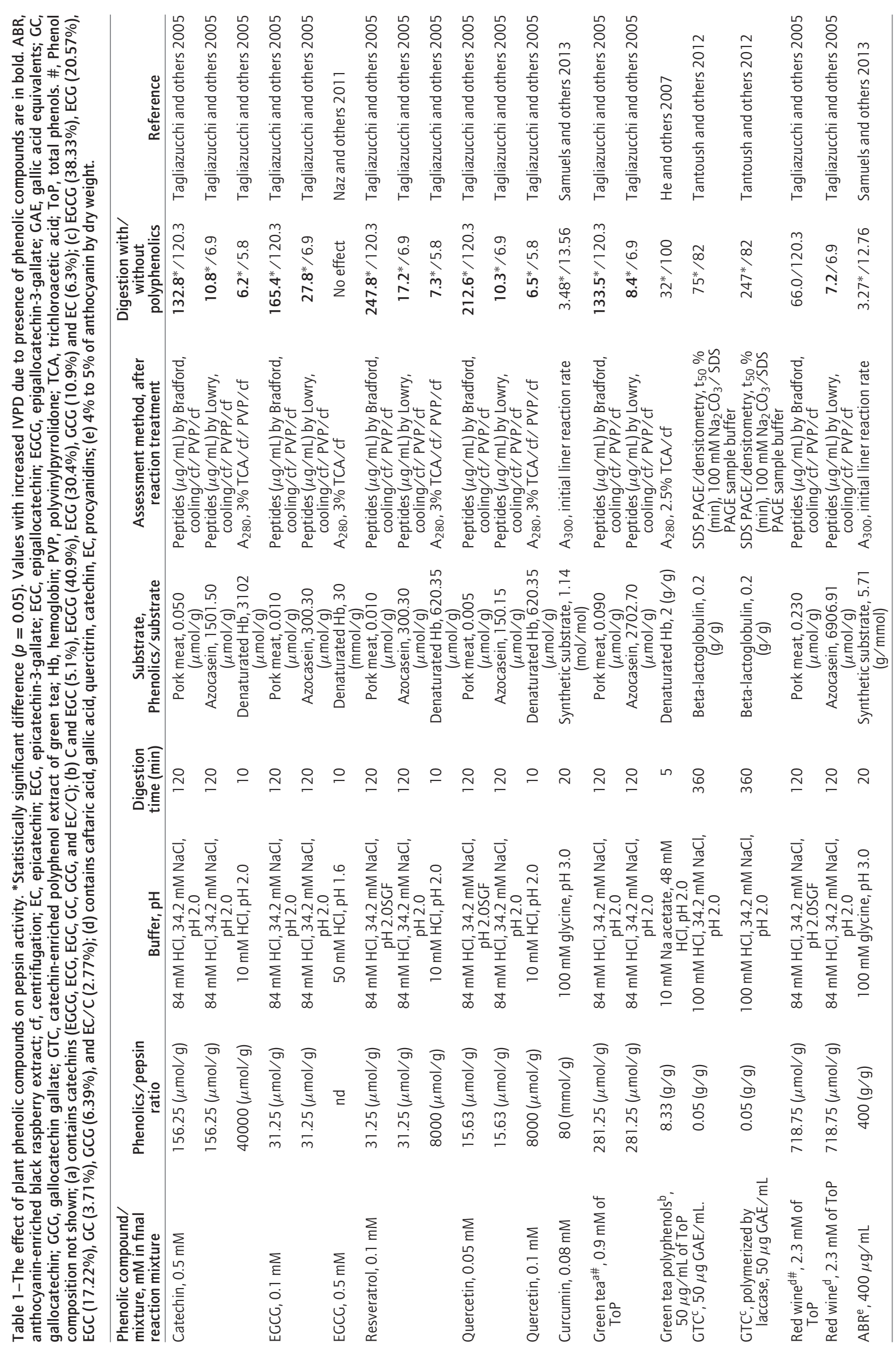


ratio and the treatment of the samples after reaction. Therefore, it is hard to pinpoint the key conditions for the inhibiting/promoting actions. Tagliazucchi and others (2005) showed an activation effect of some polyphenols and polyphenol-rich beverages on the enzymatic activity of pepsin during the digestion of several protein substrates, with the effect being concentration-dependent. The kinetics data showed that the $\mathrm{Km}$ was not changed, while the Vmax of the reaction was increased. Pepsin activity followed simple Michaelis-Menten kinetics, suggesting that the catalytic constant is increased by polyphenols.

The effectiveness of polyphenols was not related to their antioxidant potential, but may be at least partially related to their solubility, because the more water-soluble compounds such as catechin and epigallocatechin gallate (EGCG) were less active than resveratrol and quercetin which are less water-soluble. The authors did not provide a mechanism for the pepsin activation by polyphenols, but they proposed that polyphenols bind pepsin and change its 3-dimensional conformation to make it more active. In contrast, the study of He and others (2007) demonstrated inhibition of $\alpha$-amylase, pepsin, trypsin, and lipase in the presence of tea polyphenols (TPs), known as rich source of catechins, EGCG, epicatechin-3-gallate (ECG), epigallocatechin (EGC), gallocatechin (GC), gallocatechin gallate (GCG), epicatechin (EC), and catechin.

Samuels and others (2013) also demonstrated inactivation of pepsin by curcumin and anthocyanin-enriched black raspberry extract (containing $4 \%$ to $5 \%$ of anthocyanin by dry weight), but in an assay with a small synthetic substrate. Naz and others (2011) observed that EGCG inhibited $\alpha$-amylase, trypsin, and chymotrypsin, but not pepsin. In their work, Tantoush and others (2012) investigated the half-life of common food allergens in simulated GIT conditions in the pepsin digestion assay. They found that pepsin-resistant proteins such as beta-lactoglobulin and the major peanut allergens Ara h 1 and Ara h 2 degrade faster in the presence of EGCG-enriched green tea supplements (Tantoush and others 2012). The authors also demonstrated that in the case of catechins that were polymerized, for example, by the action of laccase, the result is inhibition of pepsin activity (Tantoush and others 2012).

The contradictory data on the effects of polyphenols on pepsin activity could be attributed to differences in composition and purity of the polyphenols used, experimental approach used, as well as different sources of pepsin. It should be noted that, in all their pepsin activity assays, Tagliazucchi and others (2005) treated their samples with polyvinylpyrrolidone (PVP)-40 before recording the absorbance at $280 \mathrm{~nm}$, in order to precipitate polyphenols, which absorb at $280 \mathrm{~nm}$ and react with Folin reagent, while He and others (2007) and Naz and others (2011) did not. Beside, with pork meat and azocasein as substrates, Tagliazucchi and others (2005) have stopped the reaction by cooling the samples, while when they used denaturated hemoglobin, and, in the studies of $\mathrm{He}$ and others (2007) and Naz and others (2011), nondegraded proteins were precipitated by TCA. As we mentioned, the only reliable way to distinguish net effects on protease activity itself is monitoring of protease activity using small synthetic substrate and the closest to this was the study of Samuels and others (2013), using small peptide substrate Lys-Pro-Ala-Glu-Phe-PNP-Arg-Leu-COOH. However, it should be mentioned that protease activity on small peptide substrate and protein could be quite different.

Effects of phenolic compounds on trypsin activity. In contrast to pepsin, the effects of phenolics on digestive serine proteases (trypsin, chymotrypsin, and elastase) are consistent. TPs were found to inhibit trypsin, but complete inhibition could not be achieved, and the residual activity of trypsin was maintained at $32 \%$ of the initial trypsin activity (Huang and others 2004). The Km value for trypsin remained unchanged with TP inhibition, while Vmax decreased, and the pattern of trypsin inhibition by TPs was noncompetitive. TPs also had a deactivation effect on both $\mathrm{Ku}-$ nitz trypsin inhibitor (KTI) and Bowman-Birk trypsin inhibitor (BBTI), but the inhibition was reduced dramatically when these inhibitors were already complexed with trypsin. Similarly, Huang and others (2008) showed that TP binding inhibits trypsin activity, but not completely. At a TP: trypsin mass ratio of $1.25: 1$ or greater, trypsin still retained relatively stable activity, at $53 \%$ of its initial activity. Unlike changes induced by BBTI or KTI, TP induced increased $\alpha$-helix and $\beta$-sheet and decreased random content, suggesting different mechanisms of inhibition. A clear positive relationship between the degree of polymerization of procyanidin oligomers and wine polyphenols and their ability to inhibit trypsin activity has been reported (Goncalves and others 2007). Interestingly, Mole and others (1987) observed that addition of tannic acid (TA) to a trypsin solution led to the formation of an insoluble complex, but there was an enhanced rate of autolysis of the trypsin remaining in solution. However, in the presence of an excess of bovine serum albumin (BSA), trypsin was an ineffective competitor for complex formation and it retained the ability to act as a protease without any loss of activity. Similar results were seen with the presence of both BSA and glycocholic acid, which solubilizes the otherwise insoluble TA-BSA complex. Monomers of tannins, such as catechins (condensed tannins) and gallic acid (hydrolyzable tannins), have been shown to be 1000 times less active in the inhibition of trypsin compared with high-molecular-weight TA (Loś and Podsedek 2001). Salting out of high-molecular-weight polyphenols has also been shown to reduce the trypsin-inhibiting effects of the examined extracts, further confirming that highmolecular-weight phenolic compounds were responsible for the inhibition of trypsin.

$I C_{50}$ values for trypsin inhibition (concentration of inhibitor required for $50 \%$ inhibition of enzyme activity) of caffeic acid, cinnamic acid, and ferulic acid were found to be $0.35 \pm 0.02$, $0.96 \pm 0.05$, and $1.22 \pm 0.06 \mathrm{mM}$, respectively, and caffeic acid was shown to be a noncompetitive inhibitor of this enzyme (Shahwar and others 2012). By integrating molecular docking, molecular dynamics simulation, and binding free energy calculation Cui and others (2015) found that catechins with different structures bind to the conservative S1 pocket of trypsin. The number and position of hydroxyl and aromatic groups, the structure of stereoisomers, and the orientation of catechins in the binding pocket all seem to affect the binding affinity, resulting in the following order of binding affinities: EGCG > ECG > EC > EGC. EGCG binding to trypsin ( $\mathrm{Ka} 1.82 \times 10^{5}$ at $\left.37^{\circ} \mathrm{C}\right)$ results in slight protein stabilization with increased $\beta$-sheet and decreased random content (Wu and others 2013). Quercetin derivatives were found to inhibit trypsin, with quercetin having 10 times higher potency than 4-guanidinobenzoic acid, the standard serine protease inhibitor (Danihelová and others 2013). Acerola bagasse flour extracts, rich in EC, siringic acid, catechin, EGCG, gallic acid p-cumaric acid, have also been shown to slightly inhibit trypsin (Marques and others 2016). Covalent derivatization of trypsin by polyphenols also hampers its activity. Derivatization of $\alpha$-amylase, trypsin, and lysozyme by several phenolic compounds (caffeic acid, chlorogenic acid, ferulic acid, gallic acid, $m-, o_{-}$, and $p$-dihydroxybenzenes, quinic acid, and $p$-benzoquinone) has been found to result in inhibition of enzyme activity (Rohn and 
others 2002). The decrease in activity correlated with a reduction in enzyme content of free amino and thiol groups, as well as tryptophan residues, which resulted from the covalent attachment of the phenolics to these reactive nucleophilic sites. The activity of the enzymes decreased depending on the concentration and on the number and position of hydroxyl groups of the phenolic compounds applied. Phenolic substances that are able to form quinones are much more reactive, and with increasing $\mathrm{pH}$ the reactivity of the phenolic compounds is more marked, resulting in more pronounced inhibition.

Effects of phenolic compounds on chymotrypsin activity. Naz and others (2011) reported an $I C_{50}$ value for chymotrypsin inhibition by EGCG of $46 \mu \mathrm{M}$. EGCG was capable of binding $\alpha$-chymotrypsin with high affinity (Ka $2.84 \times 10^{6}$ at $37^{\circ} \mathrm{C}$ ), stabilizing chymotrypsin conformation, as evidenced by increased $\alpha$-helix and $\beta$-sheet at the expense of decreased random content (Wu and others 2013). Interestingly, TPs potently and selectively inhibit proteasomal chymotrypsin-like activity, and therefore the proteasome is regarded as a molecular target of these polyphenols in cancer therapy (Bonfili and others 2008; Yang and others 2011). Similarly to trypsin, $\alpha$-chymotrypsin covalently derivatized with selected phenolics (chlorogenic acid, $m-, o-, p$-dihydroxybenzene, and $p$-benzoquinone) induced slower hydrolysis of selected food proteins and reduced the affinity of the enzyme for these substrates. This enzyme inhibition depended on the reactivity of the phenolics tested, as well as on the degree of the derivatization, and again phenolics forming quinones were the most effective (Rohn and others 2003).

Effects of phenolic compounds on elastase activity. Bras and others (2010) tested the inhibitory effect of procyanidins on elastase activity. It was found that more polymerized procyanidins interact stronger with the amino acids residues of the elastase active site resulting in higher inhibitory ability, in comparison to less polymerized procyanidins. Kinetic parameters indicate that the inhibition of elastase by polyphenols is reversible and competitive. Quercetin and some of its derivatives have also shown slight inhibitory activity toward elastase (Danihelová and others 2013). Crude grape pomace extract, with catechin, EC, and procyanidins B1 and B2 as major polyphenols, showed dose-dependent inhibitory activity against collagenase and elastase activity, with the fraction containing hydrophilic low-molecular weight polyphenols, in particular gallic acid, the most effective (Wittenauer and others 2015). Anti-elastase activities were observed for 9, and anticollagenase activities for 16 of the tested plant extracts, with the highest inhibitory activity for white tea, which also had the highest total polyphenol content (Thring and others 2009).

In contrast to other digestive enzymes, such as pancreatic $\alpha$ amylase, pancreatic lipase and $\alpha$-glucosidase, effect of polyphenol compounds on digestive protease activity have been barely studied (Martinez-Gonzalez and others 2017). Li and others (2014) investigated the effect of different number of hydroxyl groups in four flavonoids, quercetin, luteolin, kaempferol and apigenin, on their inhibition of trypsin activity. They have found that the binding of flavonoids to trypsin increased with an increase in the number of hydroxyl groups in parallel with their inhibitory power (quercetin $>$ luteolin $>$ kaempferol $>$ apigenin). Several studies support their finding demonstrating that binding of phenolic compounds to other proteins, such as $\alpha$ - and $\beta$-caseins (Hasni and others 2011) and $\beta$-lactoglobulin (Kanakis and others 2011; Jia and others, 2017) increases with increasing of number of hydroxyl groups of tea polyphenols. Similarly, Zeng and others (2015) demonstrated that, of tested 10 flavonoids, those with higher number hydroxyl groups, such as keampferol and quercetin, have binding constant larger and IC50 for pepsin inhibition lower than that of the flavonoids with lower number hydroxyl groups. According to several studies the inhibitory effect of individual polyphenol compounds varies with the enzyme analyzed. In addition to enzyme structure, conformation and surface polarity, it seems that enzyme size could be also factor influencing phenolic compound binding and its inhibitory activity. He and others (2007) observed higher inhibition of pancreatic amylase (61\%) by tea polyphenols than inhibition of pancreatic lipase, trypsin and pepsin $(54 \%, 38 \%$, and $32 \%$, respectively), due to its higher molecular weight compared to the other enzymes. Similarly, Xiao and others (2015) have found higher inhibition of $\alpha$-glucosidase by tannic acid compared to trypsin, having lower molecular weight.

Interestingly, Kuhnert and others (2011) compiled the Hill coefficients of a number of selected dietary polyphenol-enzyme inhibitions from the available literature, and were surprised that only about $15 \%$ of the publications quoted explicitly numerical values for Hill coefficients, of which around $70 \%$ of all Hill coefficients stated gave a value of $n>1$, with an average value of $n=4.6$. The authors proposed that the majority of reported polyphenolenzyme interactions lead to enzyme inhibition via multiple binding site allosteric denaturation rather than single site inhibition. According to this, they proposed that polyphenol compounds should be considered as compounds designed and biosynthesized with the purpose of allosteric denaturation of pest enzymes.

The findings of these studies demonstrate that inhibition of digestive proteases by polyphenol food components certainly occurs in vitro. However, there is no direct evidence to show that inhibition of protease activity occurs in the digestive system in vivo. As polyphenol reactivity is dramatically higher at higher $\mathrm{pH}$ conditions, covalent modification of digestive enzymes and consequently, inhibition of their activity is more likely to occur in the duodenal than in the gastric part of the GIT.

\section{Effects of phenolic compounds binding to proteins of saliva and gastrointestinal mucus}

Hagerman and Butler (1981) observed that a rat salivary protein showed one of the highest affinities for condensed tannin among the tested proteins and also, in comparison to gelatin, considered it to be a strong tannin-binder. In rats, the addition of condensed tannin-rich extracts to a casein diet resulted in a decrease of protein digestibility, accompanied by an increase in both the size of the parotid glands and the level of proline-rich proteins in these glands (Jansman and others 1994). It was suggested that prolinerich proteins secreted in the saliva interact with dietary tannins in the oral cavity to protect dietary proteins and reduce the antinutritional effects of the tannins. Similarly, consumption of high- condensed tannin sorghum or purified condensed tannins has been shown to increase the secretion of proline-rich proteins in rats (Mehansho and others 1983). In his review, Bennick (2002) hypothesized that salivary proteins, proline-rich proteins, and histatins serve as a screening mechanism that allows for absorption of flavonoids and exploitation of their beneficial effects, but neutralize the undesirable effects of tannins by precipitating them, therefore preventing their binding to digestive enzymes and food proteins, and their absorption from the alimentary canal.

Polyphenols can also influence in vivo protein digestibility through their interactions with mucins. It was recently demonstrated that polyphenols (naturally derived purified polyphenols and green/black tea extracts) act as cross-linkers for purified gastric and duodenal mucin leading to precipitation and gelation. The 
main active crosslinking component was found to be galloylated forms of catechins, especially EGCG, while EC and nongalloylated epicatechins had only slight effect (Georgiades and others 2014). Similarly, Davies and others (2014) demonstrated that in contrast to EC, EGCG caused aggregation of saliva gel-forming and nongel-forming mucins, altering their function as lubricants. Therefore, by mucin aggregation and changing of mucus rheological properties, phenolic compounds may have an indirect influence on dietary protein digestibility.

\section{Effects of phenolic compounds on in vitro protein digestion}

Although the results of in vitro digestion models are often different from those found used in vivo models, in vitro digestion models are useful as they are less expensive and can provide results in a short time. Many studies have shown that polyphenols decrease protein digestion in vitro because of covalent, as well as noncovalent interactions of polyphenols with proteins. Table 2 summarizes in detail in vitro studies of the effects of phenolic compounds on protein digestibility. It can be observed that all studies were done under quite different conditions, including phenol-to-protein ratio, enzyme-to-protein ratio, digestion time and different assessment method. Moreover, phenol to protein ratio and enzyme to protein ratio are differing more than two orders of magnitude between the studies. Since after consumption of phenolic compound-rich foods/beverages their concentration in gastric and intestinal compartment is likely to reach $\geq \mathrm{mM}$ (Halliwell 2007), the highest concentrations of phenolic compounds in digestion mixtures in the mentioned studies seems to be realistic. Also, different protein substrates were used, from protein-rich whole food matrices to purified proteins, and from highly to poorly digestibile proteins. Different methods used include determination of insoluble or soluble fraction of proteins, with or without protein precipitation (TCA, picric acid), by peak area after RP HPLC, Bradford assay, $\mathrm{A}_{280}$, Dumas combustion method, released amino acids, and disappearance of protein bands after SDS PAGE/densitomtry. Some of the methods monitor disappearance of intact or almost intact substrate, while other determine released peptide fraction or amino acids. One of problematic issues is enzyme to protein ratio. In the most of the studies only $\mathrm{w} / \mathrm{w}$ ratio is provided (or can be calculated), and even where enzyme activity per protein weight is given, enzyme activity was taken from manufacturer specification rather than determined immediately before experiment. Therefore actual enzyme activity per protein weight might be questionable. All these parameters highly influence the final estimation of protein digestibility and, although the digestibility was estimated in comparison to corresponding control samples (without phenolic compound addition), it is hard to compare these studies between each other.

However, by using protein substrates with added or noncovalently complexed polyphenol it is hard to reliably determine to what extent the reduction in protein digestibility is due to digestive enzyme inhibition and to what extent it is due to inaccessibility of the protein substrate. The protein amino acid composition, as well as their structure are the main determinants of protein affinity to phenolic compounds, therefore defining accessibility of the protein substrate. The proline residues are regarded to play a key role in protein-polyphenol interactions (Charlton and others 2002). Beside, it was shown that aromatic amino acid residues interact with phenolic compounds by hydrophobic interactions (Charlton and others 2002), and histidine residues are also considered as possible binding sites for phenolic compounds (Wróblewski and others 2001). Bohin and others (2012) observed that gelatins $\mathrm{A}$ and $\mathrm{B}$ displayed a lower affinity to EGCG than $\beta$ casein due to the higher content of aromatic amino acids and histidine in $\beta$-casein than in gelatins, although gelatins have higher total proline contents than $\beta$-casein. In comparison to proteins with less ordered structure, such as $\beta$-casein, gelatins and phosvitin, globular proteins demonstrate the lower affinity to phenolic compounds due to lower accessibility of amino acid residues (Bohin and others 2012). Although having globular structure, BSA and human serum albumin are exceptions, as these proteins are known to bind many ligands, including phenolic compounds (Table S1). Noncovalent interactions of polyphenolic compounds could stabilize or destabilize protein structure, therefore changing their accessibility to proteolytic attack. The binding of catechins resulted in reduction of $\alpha$-helix and $\beta$-sheet and increase of random coil in casein (Hasni and others 2011), while their binding to $\beta$-lactoglobulin (BLG) increased $\beta$-sheet and $\alpha$-helix, suggesting stronger structural stabilization of the protein (Kanakis and others 2011). On the other hand, noncovalent phenolic compound binding can hinder sterically the accessibility of protein to enzyme. Covalent interactions could also induce protein partial unfolding resulting in increased protein digestibility. Quinones, generated by phenolic compound oxidation, react with amino groups in protein resulting in covalent binding of polyphenol compounds to proteins. Trypsin is unable to act on sites with modified lysines due to steric effects as well as the loss of positive charge on the $\varepsilon$-amino group, necessary for stabilization of the aspartate residue in the trypsin catalytic center (Zee and Garcia 2012). Consequently, more extensive covalent phenolic binding to protein would increase protein digestibility by trypsin because of more extensive protein unfolding, but resulting peptides would be longer, and semi-resistant to trypsin due to reduced number of positively charged residues.

In the last decade there have been increasing developments in technologies for food fortification with phenolic compounds. These technologies provide, on the one hand, delivery of phenolics benefits in a portable and shelf-stable format and, on the other hand, their valorization from nonpalatable plant parts, such as skins and peels, which are usually discarded. Although proteins, as food matrix components, protect phenolic compounds via interactions with them, these interactions can also result in the reduction of nutritive value of the food product. Therefore, the creation of functional food product fortified with phenolic compounds should be designed with great attention and, in addition, to the testing of other properties of these products, the effects of added phenolic compounds on protein in vitro digestibility should be also tested.

\section{Effects of noncovalent phenolic compound binding on in vitro protein digestion}

Effects of noncovalent phenolic compound binding on in vitro protein digestion in protein-rich matrices and food protein fractions. Many in vitro studies have shown that the addition of polyphenol sources to protein-rich matrices decreases protein digestibility. Supplementation of breads with onion skin, an excellent source of quercetin and its derivatives, has been shown to reduce in vitro protein digestibility (IVPD) (Swieca and others 2013). Interestingly, after fortification of bean paste with onion skin phenolics (5 to $50 \mathrm{mg}$ per $100 \mathrm{~g}$ of bean) no significant effect was observed on the albumin IVPD, while digestibility of globulins had decreased from $70 \%$ up to $55 \%$ after gastric, and from $93 \%$ up to $80 \%$ after intestinal digestion (Seczyk and others 2015). The addition of black tea extract significantly lowers pancreatin digestibility of egg yolk proteins in a concentration-dependent manner 


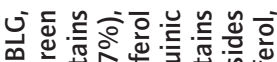

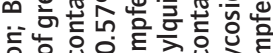

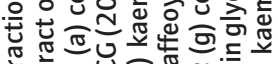

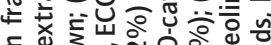

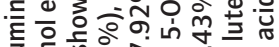

흠

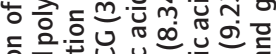

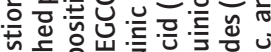

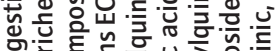

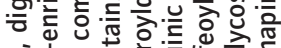

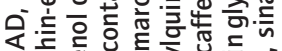

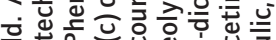

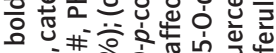

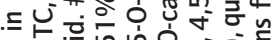

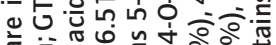

证.

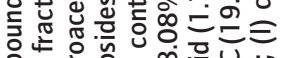

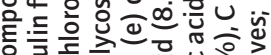

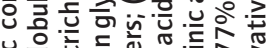

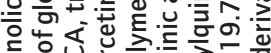

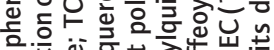

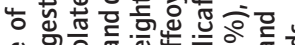

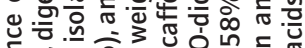

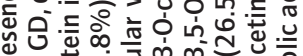

产

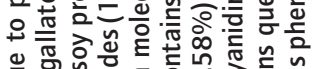

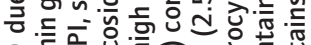

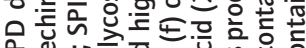

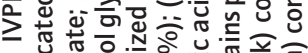

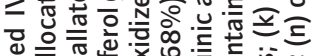

ॐ

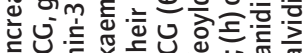

.

든

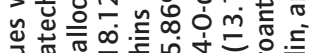

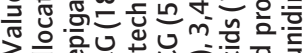

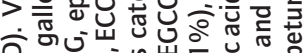

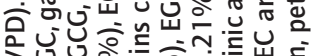

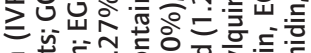

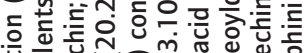

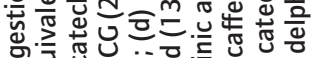

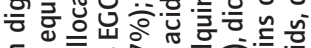

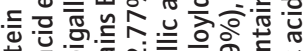

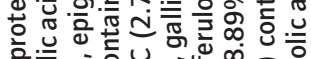

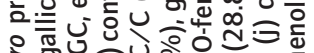

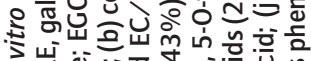

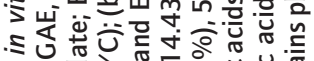

ㄷ.

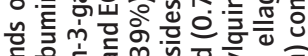

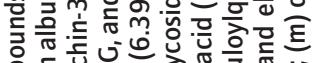

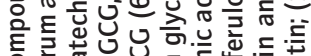

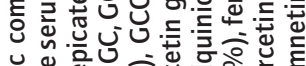

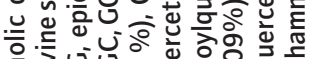

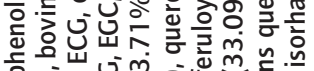

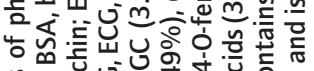

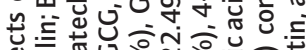

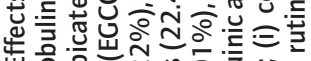

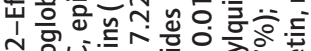

น

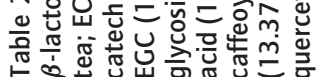

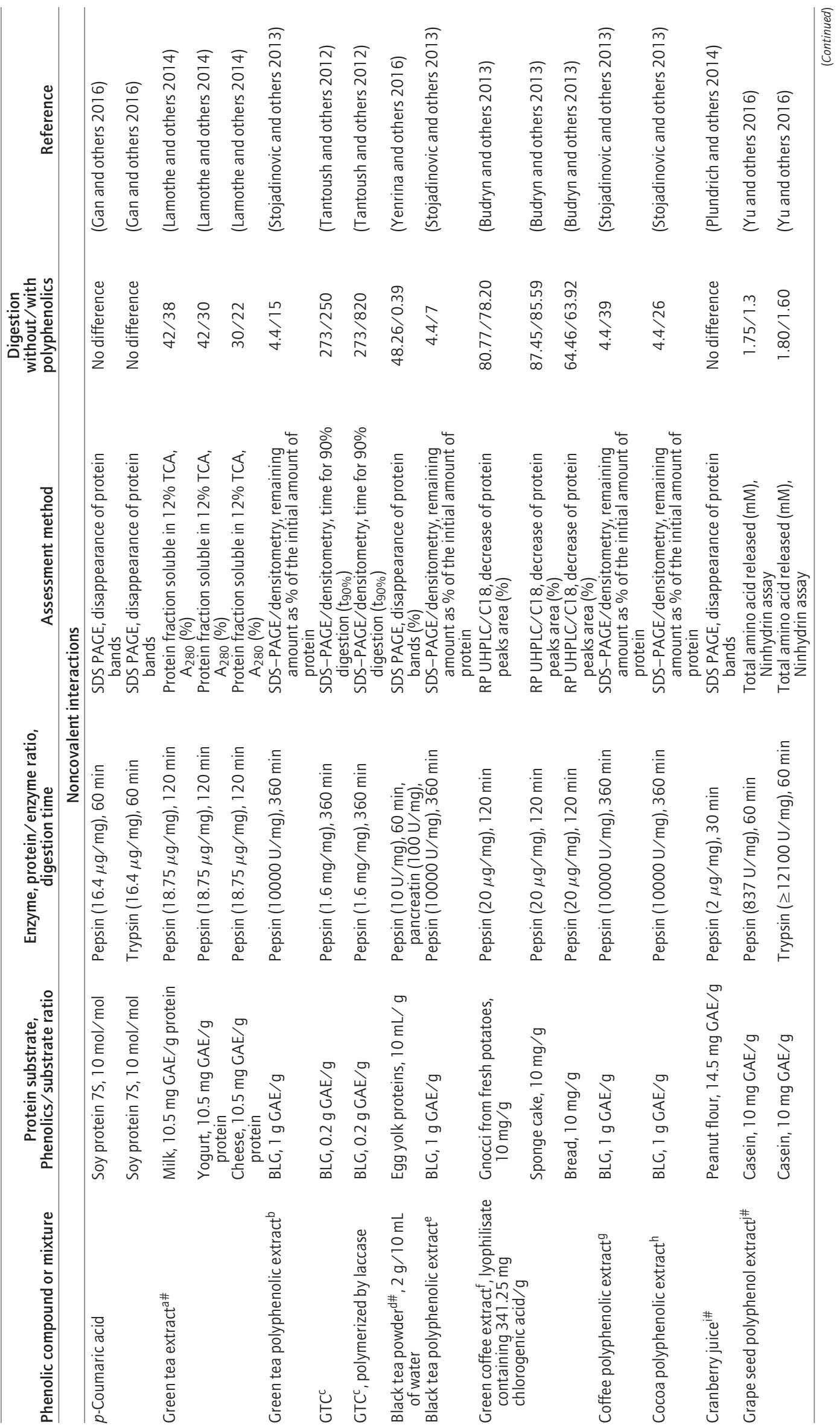




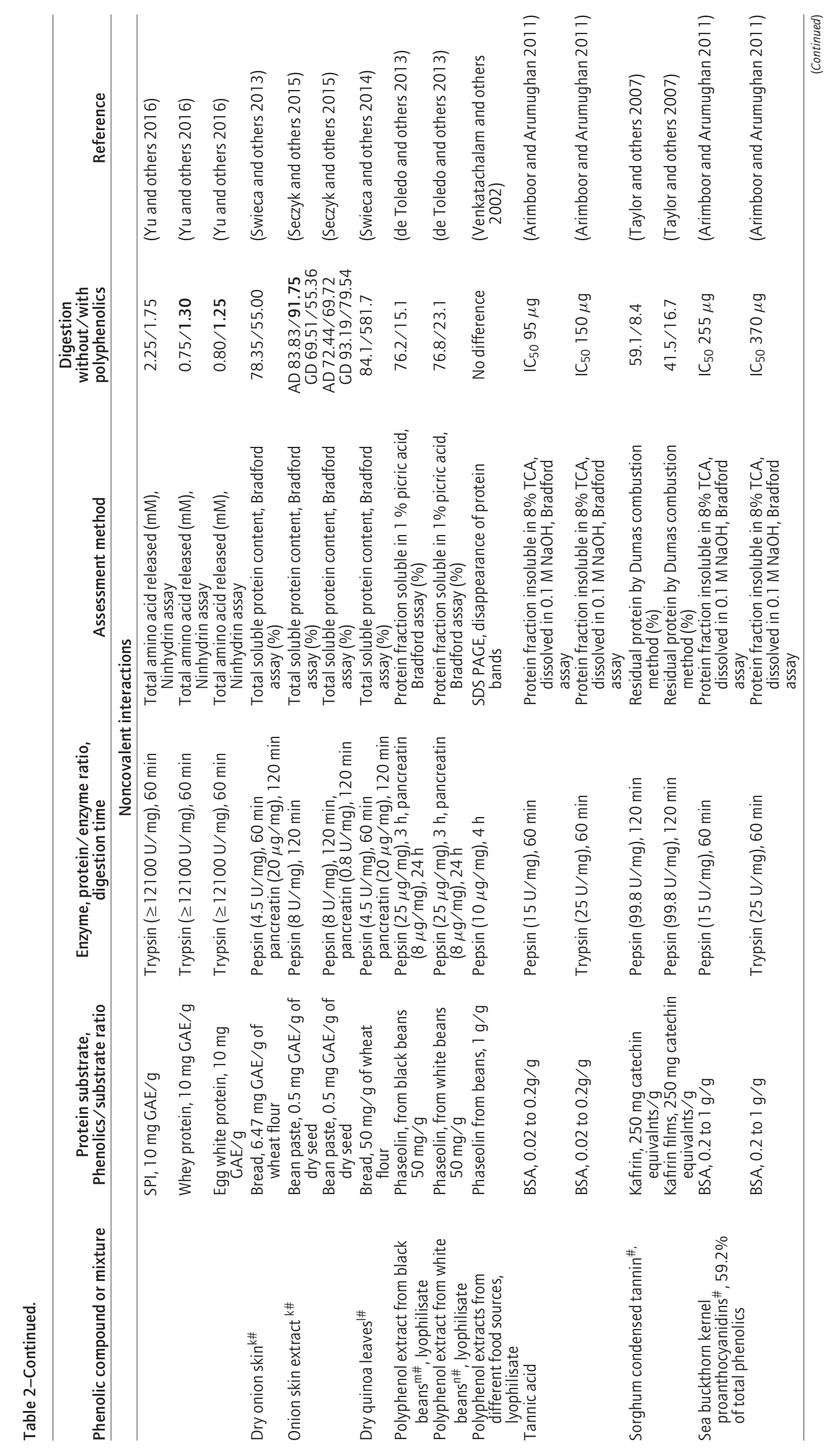




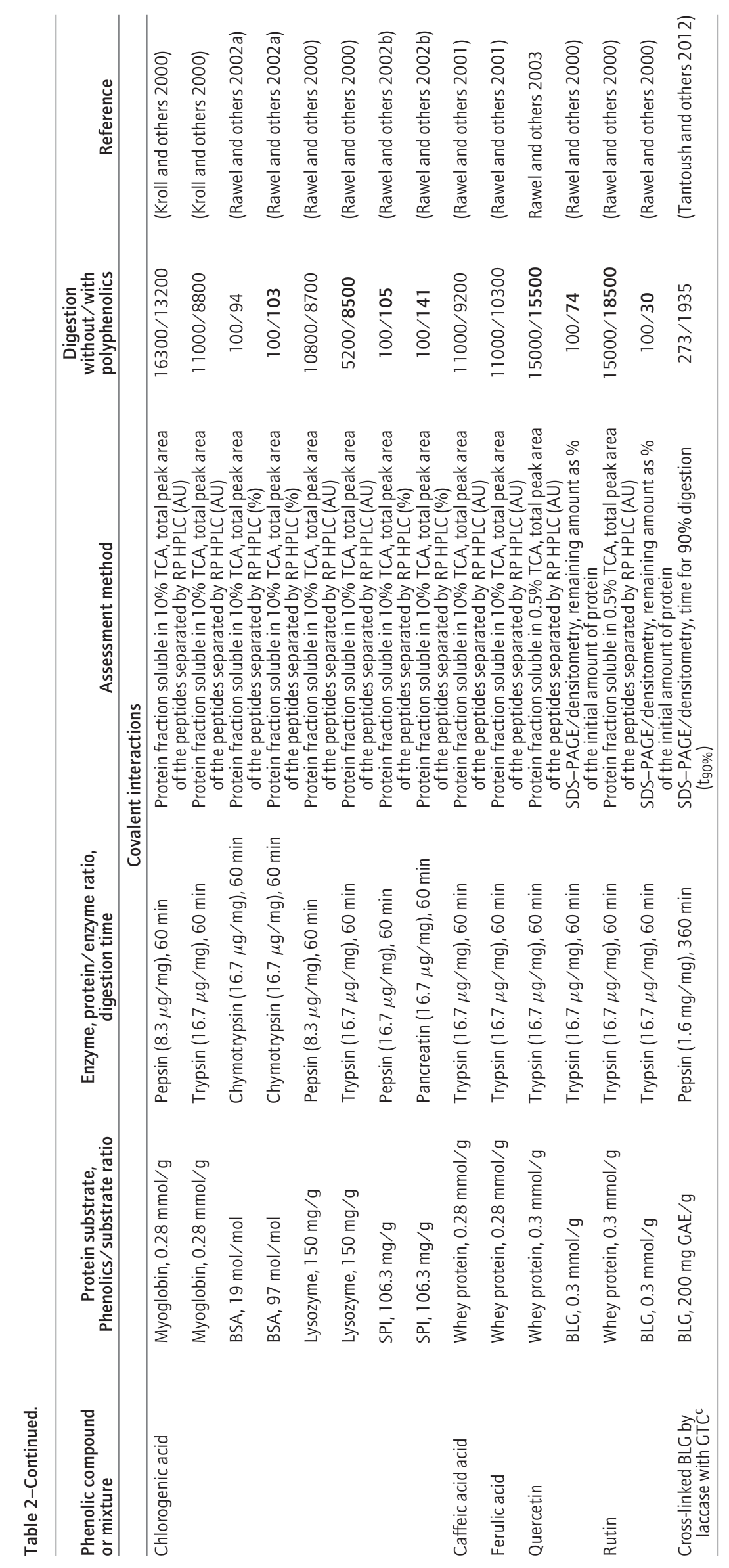


(Yenrina and others 2016). The addition of green tea extract to milk, yogurt, and cheese significantly decreased proteolysis in the gastric phase, but had no effect in the intestinal phase. As polyphenols form complexes with milk proteins $(\alpha$ - and $\beta$-caseins and $\beta$-lactoglobulin), they sterically hinder the accessibility of pepsin, resulting in increased protein stability during digestion. However, the presence of dairy matrices significantly improved polyphenol stability in the intestinal phase and increased antioxidant activity. Since cheese was the matrix most resistant to digestion, it might be best suited for the protection of molecules that are very sensitive to the gastrointestinal environment (Lamothe and others 2014). In contrast, the addition of green coffee extract to several foods (gnocchi, sponge cake, bread, mayonnaise, marshmallows, caramel candies, and jellies) resulted in negligible (maximum 3\%) decreases in IVPD by pepsin (Budryn and others 2013). Similarly, IVPD of wheat flour bread fortified with quinoa leaves $(1 \%$ to $5 \%$ ) was only slightly decreased, with the lowest IVPD of bread supplemented with 3\% quinoa leaves (a reduction of 3.2\% in respect to the control) (Swieca and others 2014).

Peanut flour fortified with polyphenol-rich plant juices and extracts demonstrated reduced IgE-binding to one or more peanut allergens. Although there was no difference in peanut allergen digestibility, IgE-binding to pepsin-resistant peptides of Ara h 6 was dramatically reduced (Plundrich and others 2014). Treatment of soy protein $7 \mathrm{~S}$ with $p$-coumaric acid, caffeic acid, gallic acid, and chlorogenic acid did not inhibit protein degradation by pepsin at $\mathrm{pH} 2$ and $\mathrm{pH} 4$, and trypsin at $\mathrm{pH} 7.5$, even when the mass ratio of phenolic acids to soy protein 7S reached 10:1 (Gan and others 2016). Yu and others (2016) demonstrated that casein digestion by pepsin increased with increasing grape seed polyphenol extract (GSP) concentration until GSP concentration reached $0.04 \mathrm{mg} / \mathrm{mL}$, and then decreased. In contrast to casein, digestibility of soy protein isolate (SPI) and egg white protein increased gradually with increasing GSP concentration. However, with increasing concentration of GSP digestibility of casein and SPI by trypsin decreased, whereas digestibility of egg white and whey protein increased.

Among important food products, sorghum, millet, as well as various types of beans and peas, may contain considerable amounts of tannins. Although these foods contain proteins resistant to proteolysis due to their structural properties, such as phaseolin in beans, kafirins in sorghum, and $\gamma$-conglutin in lupin, noncovalent interactions of phenolic compounds with these proteins additionally decrease their digestibility. Polyphenols interfere with the digestibility of beans by decreasing the hydrolysis of phaseolin, especially for darker beans, which have a higher condensed tannin content than white beans. With the addition of polyphenolic crude extract there is a significant decrease in the in vitro digestibility of phaseolins by pepsin/pancreatin (de Toledo and others 2013). However, Venkatahalam and others demonstrated that phenolic compounds from diverse food sources did not interfere with phaseolin proteolysis by pepsin in vitro (Venkatachalam and Sathe 2003). Kafirins, the main sorghum proteins, bound to condensed tannins, as well as edible films made from tanninbound kafirin, had lower in vitro pepsin digestibilities than unbound kafirins (Taylor and others 2007). Digestion of lupin seed globulins by pepsin and by pepsin/pancreatin causes the release of bound native flavonoids, mainly apigenin glycosides (Czubinski and others 2012). This study confirmed the resistance of lupin glycoprotein $\gamma$-conglutin to digestion with pancreatin, and the authors speculated that flavonoids liberated from other lupin proteins, as a result of pancreatin-catalyzed digestion, are bound by $\gamma$-conglutin. The authors related the insensitivity of $\gamma$-conglutin to digestion to electrostatic attraction between positively charged $\gamma$-conglutin and partially ionized flavonoids at $\mathrm{pH}$ 7.5. In a followup study, they found support for this hypothesis by showing that $\gamma$-conglutin and vitexin form a static complex with flavonoids, observed using fluorescence-quenching measurements (Czubinski and others 2014). Similar to beans, white-grain varieties of finger millet have a lower phenolic content than brown-grain varieties and, thus, higher IVPD values.

Effects of noncovalent phenolic compound binding on in vitro digestion of purified proteins. A decrease in protein digestibility as a result of the addition of polyphenols to purified food proteins has also been reported. BSA is the most investigated food protein regarding interactions with phenolic compounds. There are numerous of studies investigating interactions of BSA with phenolic compounds, and the most of them reporting binding parameters (Table S1). However, there is only one study investigating effects of phenolic binding to BSA on its digestibility. Therefore it is obvious that, in comparison to interactions of food proteins with phenolic compounds, changes in protein digestibility, as consequence of these interactions, is still neglected topic.

Hydrolysis of BSA by pepsin and trypsin has been shown to be reduced by the binding of sea buckthorn proanthocyanidins (Arimboor and Arumughan 2011), and higher digestibility by trypsin was attributed to decreased affinity of condensed tannins and partial dissociation of the protein-tannin complex at basic $\mathrm{pH}$. It was shown that the formation of aggregates is increased with increasing molecular weight of flavonoid polymers, with increasing numbers of terminal galloyl groups, and with an increasing proline contents in the polypeptides (Bordenave and others 2014). However, there is no linear relationship between the molecular weight of polyphenols and protein affinity due to the lower solubility of higher-molecular-weight tannins and the higher solubility and reactivity of low-molecular-weight tannins Observation that structurally flexible gallotannins bind to gelatin and BSA with similar affinity, while more rigid ellagitannins bind stronger to gelatin than to BSA, implies that a structural rigidity of the condensed tannins may contribute to their low affinity for BSA (Frazier and others 2010). However, it has been shown that the ability of tannins to precipitate proteins is a good predictor of protein digestibility. Stojadinovic and others (2013) demonstrated a positive correlation between the binding constants of dietary polyphenols (from green tea, black tea, cocoa, and coffee extracts) for BLG and the halflife of protein decay in simulated gastric conditions. Polyphenols bound to BLG protected enzyme target sites in BLG, although no significant precipitation of BLG occurred at $\mathrm{pH}$ 1.2. The delayed simulated intestinal digestion of BLG was seen only in the presence of cocoa and coffee polyphenolic extracts, and it was not as pronounced as it was for pepsin digestion. Although the high affinity binding of cocoa and coffee polyphenolic extracts to BLG at $\mathrm{pH} 7.2$ might protect the protein from the proteolytic attack, their destabilizing effect on BLG secondary structures diminish protein resistance to digestion, resulting in a net minor delay in intestinal digestion of BLG.

\section{Effects of covalent phenolic compounds binding on in vitro protein digestion \\ Effects of phenolic compounds covalently bound to proteins} at alkaline pH. Several studies have shown that proteins covalently derivatized by polyphenolic compounds, achieved by simple 
incubation at basic $\mathrm{pH}$, become resistant to digestion by GIT proteases. Derivatization of myoglobin with phenols led to a corresponding detrimental effect on in vitro digestion by trypsin, chymotrypsin, and pepsin (Kroll and others 2000), and the effect increased in accordance with the reactivity of the phenolics tested. Digestion of whey proteins derivatized with phenolics by trypsin, chymotrypsin, pepsin, and pancreatin has also been shown to be reduced (Rawel and others 2001), with tea extract having the greatest effect, followed by coffee, potato, and pear extracts. In both of these studies, the authors concluded that protein derivatization by phenolic substances makes tryptic degradation difficult due to the reaction of phenolics with $\varepsilon$-amino groups of lysine side chains. However, in a further study, Rawel and others (2002a) made the interesting observation that BSA lowly derivatized with chlorogenic acid proved to be the most difficult to digest by trypsin. The ease of tryptic digestion increased with increasing levels of attached chlorogenic acid, but digestion still remained difficult in comparison to that of unmodified BSA. The authors explained this observation by raising the possibility that derivatization of BSA may cause the protein molecules to expand due to progressive unfolding, thereby better facilitating tryptic attack. Derivatization of lysozyme by chlorogenic acid has been shown to adversely affect its digestion by pepsin, while tryptic and chymotryptic hydrolysis seemed to be favored (Rawel and others 2000). Both effects were attributed to conformational and structural changes of lysozyme resulting from derivatization. The same group has shown in other work that treatment with various phenolic compounds promotes the tryptic, chymotryptic, and pancreatic hydrolysis of soy proteins, whereas peptic digestion is more or less unaffected (Rawel and others 2002b). The unexpected increase in tryptic digestibility observed in these studies suggests that the proteolytic digestion of protein-phenol derivatives is dependent on many factors, including the amino acid composition, molecular size, and native structure of the proteins, and their structural constellations after derivatization with phenolic compounds. The covalent modification of whey proteins and BLG by quercetin and rutin was also found to increase IVPD by trypsin, chymotrypsin and pepsin, with rutin being more effective due to its bulkiness resulting from the attached rhamnosylglucoside (Rawel and others 2003). It should be noted that, in all of these studies, proteins were partially denatured with urea before IVPD tests to account for the fact that, generally, ingested proteins are also partly denatured as a result of processing and cooking.

Effects of phenolic compounds covalently bound to proteins by polyphenol oxidase mediation. In addition to alkaline $\mathrm{pH}$, phenolic compounds could be covalently bound to proteins by the action of oxidases. Low-molecular-mass phenolic compounds have been reported to enhance the crosslinking of proteins by phenol oxidases such as tyrosinase and laccase (Selinheimo and others 2007), and phenolics incorporation into crosslinked protein networks has been demonstrated to result in disturbed protein digestibility. In the study of Stanic and others (2010), $\beta$-casein was treated with tyrosinase, tyrosinase, and laccase in the presence of caffeic acid. After a short period of pepsin digestion $(15 \mathrm{~min})$, a high portion of the control casein was already digested, while in modified samples, crosslinked caseins of high molecular weight were undigested, and remaining monomeric protein was digested efficiently. The presence of caffeic acid hampered digestion by pepsin, and this effect was most pronounced for the tyrosinase/caffeic acid crosslinked casein. All the crosslinked proteins were readily digested after proteolysis for $1 \mathrm{~h}$. During simulated gastrointestinal digestion (pepsin/pancreatin), BLG cross-linked by laccase in the presence of caffeic acid showed resistance, and it was completely digested after $60 \mathrm{~min}$ of simulated intestinal digestion, in comparison to BLG which was degraded within 5 min (Stojadinovic and others 2014). When Tantoush and others (2011a) treated BLG with laccase in the presence of phenolics from sour cherry extract (SCE), pepsin digestion of the remaining monomeric BLG in a sample treated by laccase/SCE proceeded more rapidly than proteolysis of control BLG or BLG exposed only to laccase. However, traces of high-molecular-weight crosslinked proteins remained undigested even after prolonged exposure to pepsin. BLG exposed to SCE without the addition of laccase was more resistant to trypsin than control BLG. Modification of BLG with laccase and apple polyphenols was found to decrease the biphasic pepsin-pancreatin digestibility of the remaining monomeric, as well as crosslinked, protein (Tantoush and others $2011 \mathrm{~b}$ ). In a further study (Tantoush and others 2012), the same authors investigated the in vitro gastric digestion of several food allergens such as BLG, $\alpha$-lactalbumin (ALA), and peanut allergens in the presence of a catechin-enriched polyphenol extract of green tea (GTC), oxidized polyphenols, and phenol oxidase-processed mixtures of food allergens and GTC. Pepsin-resistant proteins, such as BLG and peanut allergens, degrade faster in the presence of catechin-enriched green tea polyphenols. Phenol oxidase-polymerized GTC adversely affected digestion of BLG and ALA, but not peanut extract proteins. The protective effect of polyphenols correlated well with the ability of proteins to form insoluble complexes with oxidized catechins. Crosslinking of proteins and polyphenols further extended the half-lives of BLG and ALA, suggesting that catechin-enriched green tea polyphenols facilitate pepsin digestion of major food allergens, but hamper their digestion if oxidized and polymerized by phenol oxidase. These studies suggest that polymerized proteins become resistant to proteolysis after crosslinking. However, remaining monomeric proteins are also resistant to degradation if they are shielded by the binding of high-molecularmass polyphenols, while they are more prone to proteolysis if the binding of low-molecular-mass polyphenols results in changes in protein conformation that allow better accessibility for protease attack.

The level of aggregation of dietary proteins is considered to be important intrinsic factor for the development of an allergic response to food proteins. The enzymatic cross-linking of food proteins to form high-molecular-weight aggregates may alter their sensitization potential and allergenicity. Liu and others (2017) cross-linked tropomyosin in the presence of caffeic acid with tyrosinase (CTC) or horseradish peroxidase (CHP), and demonstrated that, compared with native tropomyosin or CTC, CHP was more easily digested into small fragments. Both CTC and CHP induced oral tolerance and had reduced allergenicity, but with CHP showing higher potential. Proteins from peanut extract, crosslinked with tyrosinase from Agaricus bisporus by polyphenols present in the extract, showed increased aggregation and survival of higher-molecular-weight fragments for a prolonged time in in vitro pepsin digestion, as opposed to peanut extract crosslinked with tyrosinase from $T$. reesei, which gave aggregates of lower molecular weight and was digested in a similar way to untreated peanut proteins. However, cross-linking of peanut proteins by both tyrosinases did not significantly change the allergenic or tolerizing properties of peanut (Radosavljevic and others 2014). 
Effects of phenolic compounds on in vivo protein digestion

In vivo protein digestion methods, based on feeding animals or humans, usually provide the most trustworthy picture of protein digestibility, but they are time-consuming and costly. Nitrogen balance studies were previously the most suitable practical method for evaluating in vivo protein digestibility, but practical difficulties and the poor sensitivity of the nitrogen balance method has led to adoption of the protein digestibility-corrected amino acid score (PDCAAS) approach, which was adopted by FAO/WHO (1991) as the preferred method for the measurement of protein value in human nutrition (Millward and others 2008). It is generally recognized that the abilities of rats and humans to digest a variety of foods are similar, and therefore the PDCAAS method includes the use of young rats for predicting the protein digestibility of foods.

The effects of tannins on in vivo protein digestibility appear to be dependent on both the level and the origin of the tannins, as well as on the animal species involved. The addition of increasing amounts of condensed tannin-rich fava bean hulls or extracts to a casein diet resulted in a linear decrease in apparent protein digestibility, monitored as rat fecal total and individual amino acids (Jansman and others 1994).

Interaction between polyphenols and proteins during the hydrothermal treatment of buckwheat reduced the digestion of proteins through the small and large intestine in a rat model (Skrabanja and others 2000). Boiled buckwheat with a moderate polyphenol content showed significantly lower true protein digestibility in comparison to buckwheat without hydrothermal treatment, but significantly higher true protein digestibility in comparison to similarly treated high-polyphenol buckwheat. When rats were fed diets containing $20 \mathrm{~g} / \mathrm{kg}$ of catechin or TA, only small amounts of ingested catechin and TA appeared in feces with structural modifications, indicating that intestinal absorption and degradation had occurred. TA induced an increase in total dry matter excretion, as well as in the fat, protein, and water contents of feces, while catechin only affected fat excretion (Bravo and others 1994). Green and black tea and coffee have been shown to have significantly negative effects on true protein digestibility and the biological value of soya-bean meal or barley diets in rats, while cocoa had no effect (Eggum and others 1983). Shahkhalili and others (1990) demonstrated that extracts of tea increased the excretion of nitrogen in feces due to decreased digestibility of dietary protein, but also due to a marked stimulation of the excretion of endogenous (body) nitrogen, as shown through the use of the stable isotope of nitrogen $\left({ }^{15} \mathrm{~N}\right)$. These studies, therefore, indicate that foods rich in polyphenols have varying effects on nitrogen excretion in feces and that, in the case of tea at least, the loss of endogenous nitrogen may be a major contributing factor. The authors supposed that colon microorganisms may enhance the digestibility of proteins, countering the effect of protein-polyphenol interactions. Zdunczyk and others (2002) reported that it is very difficult to obtain appreciably wholesome effects through diet supplementation with polyphenol extracts without a reduction in protein digestibility and protein efficiency ratio. They demonstrated that the addition of large amounts of catechin extract $(0.8 \%)$ to diets, effective in reducing the total cholesterol and the LDL fraction in serum, also caused a reduction in protein digestibility and protein efficiency ratio. The digestibility of whey proteins was diminished by the presence of chlorogenic acid, and nitrogen excretion was significantly higher in the feces and lower the in urine of rats fed with highly derivatized BLG as compared with lowly derivatized and underivatized
BLG (Petzke and others 2005). The authors speculated that a low-quality plant protein, rather than the high-nutritional-quality whey proteins, may show more distinct effects; and, indeed, soy proteins derivatized with chlorogenic acid/quercetin showed more marked effects (Rohn and others 2006). Rats fed with soy protein derivatives showed increased excretion of fecal and urinary nitrogen, and true nitrogen digestibility and net protein utilization were adversely affected. PDCAAS was decreased for lysine, tryptophan, and sulfur-containing amino acids.

From the physiological aspect, having in mind that the essential amino acids are limited in many proteins, the binding of secondary plant metabolites to proteins may be considered crucial. This is especially important for regions of the world where nutrition is mainly based on plant food, with lower-quality plant proteins and high amounts of secondary plant metabolites plant food. In addition to the effects of polyphenols on protein digestibility, an effect of proteins on polyphenol availability has also been observed in several in vivo studies. Consumption of fruit and cacao with milk/yogurt resulted in lower plasma levels and/or urinary excretion of polyphenols in comparison to their consumption with water (Bohn 2014). Therefore, reduced protein digestibility as a consequence of polyphenol binding at least partly contributes to decreased polyphenol release from food matrices during digestion, and hence to their reduced bioavailability. On the other side, by binding to protein phenolic compounds get protected from the harsh conditions in stomach.

\section{Food Processing Methods for the Reduction of Antinutritional Effects of Phenolic Compounds}

Diets in developed countries are mostly based on highlydigestible proteins of animal and vegetable origin, while those in developing countries are predominantly based on poorly-digestible proteins from less refined cereals and legumes due to the presence of less-digestible protein fractions, high levels of insoluble fiber, and high amounts of antinutritional factors, including phenolic compounds.

Although legumes constitute one of the most abundant and least expensive sources of protein in human diets, their utilization is limited, largely due to the presence of antinutritional compounds, including free phenolics and tannins. Among important food products, sorghum, millet, and various types of beans and peas may contain considerable amounts of tannins (up to $72 \mathrm{~g} / \mathrm{kg}$ ), which adversely affect the digestibility of proteins and reduce the quality of these foods (Gilani and Sepehr 2003). In addition, celiac disease affects millions of individuals, and they are resigned to avoidance of products containing the cereal grains such as wheat, rye, and barley. Therefore, millet, sorghum, quinoa, amaranth, and buckwheat, phenolic compounds-rich ancient grains, are alternatives for the production of inexpensive high-quality gluten-free food products.

Therefore, several technological treatments have been developed to reduce the phenolic compound contents of these foods and thus increase protein digestibility. These treatments include soaking in water or alkaline solutions, heat treatment with or without high pressure (autoclaving and cooking, respectively), dehulling, extrusion, malting, fermentation, germination, and addition of chemicals with a high affinity for tannins, such as polyvinylpyrrolidone and polyethylene glycol, or proteins, such as gelatin. Although sorghum tannins inhibit digestive enzymes, their antinutritional effect is considered to be consequence of formation of less-digestible 


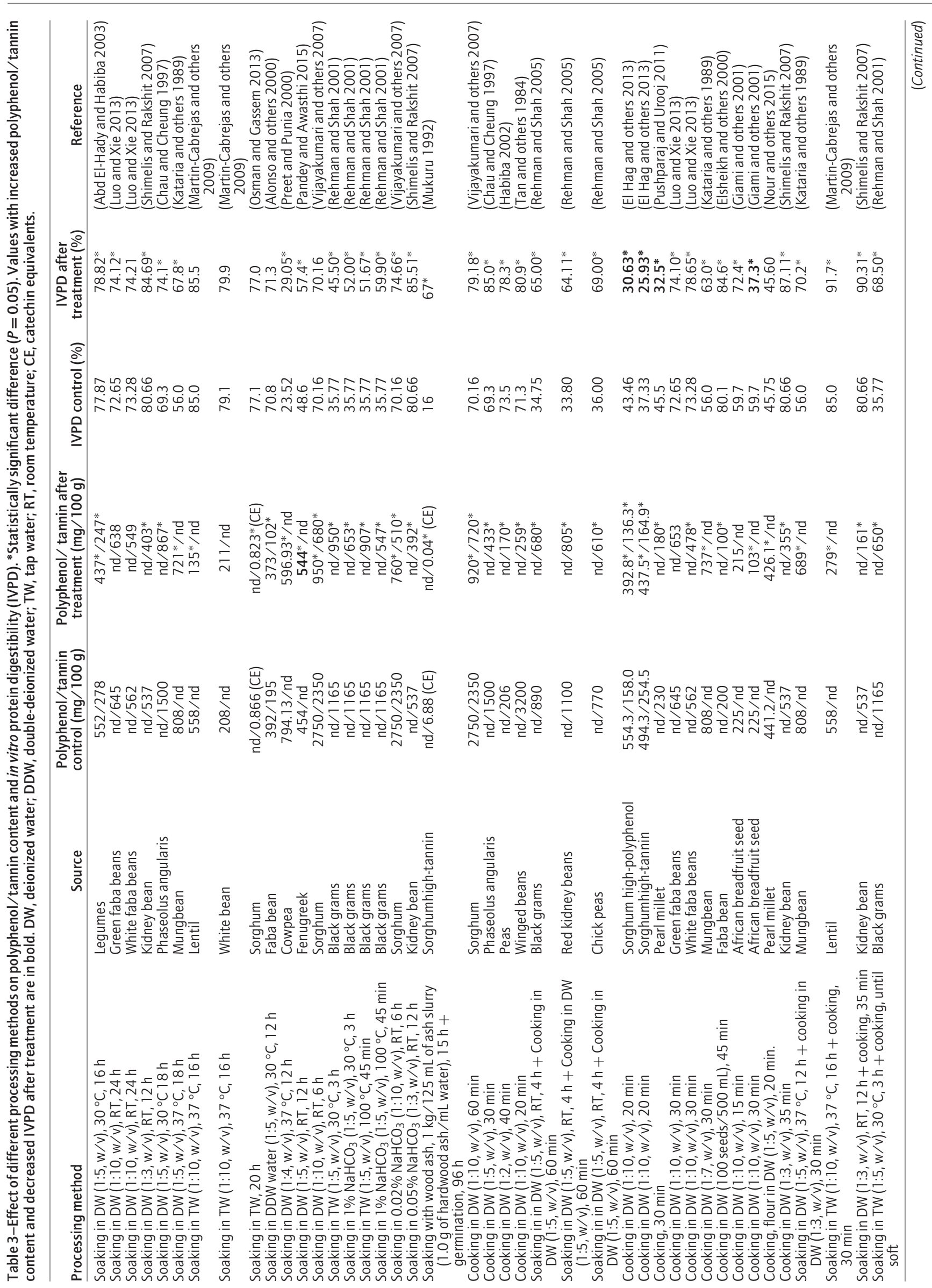




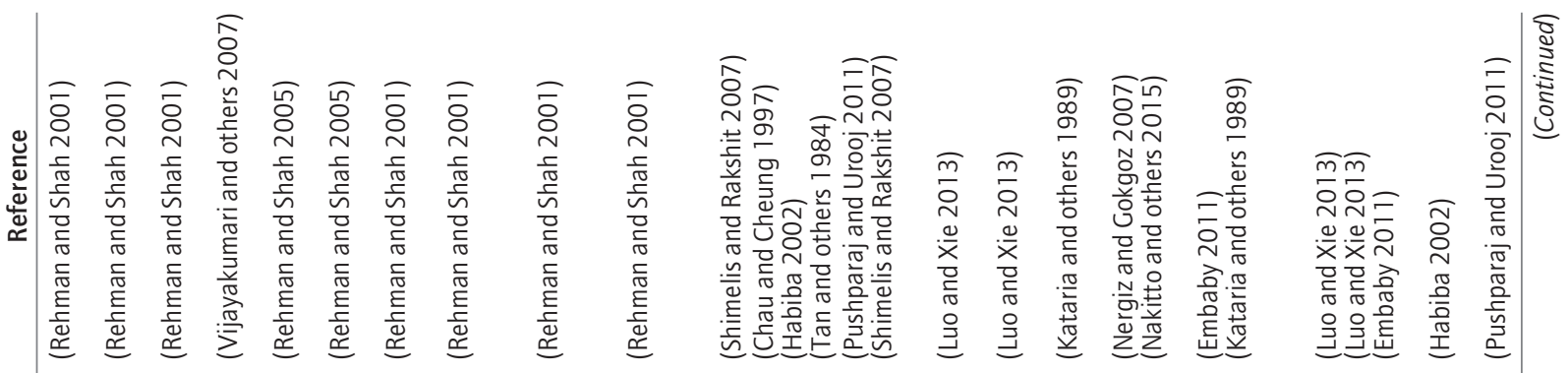

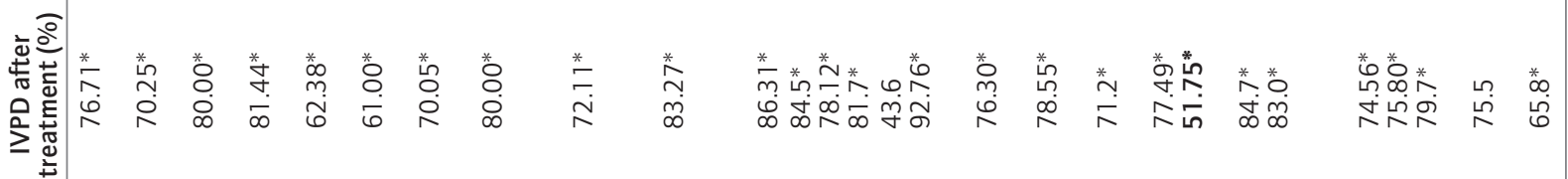

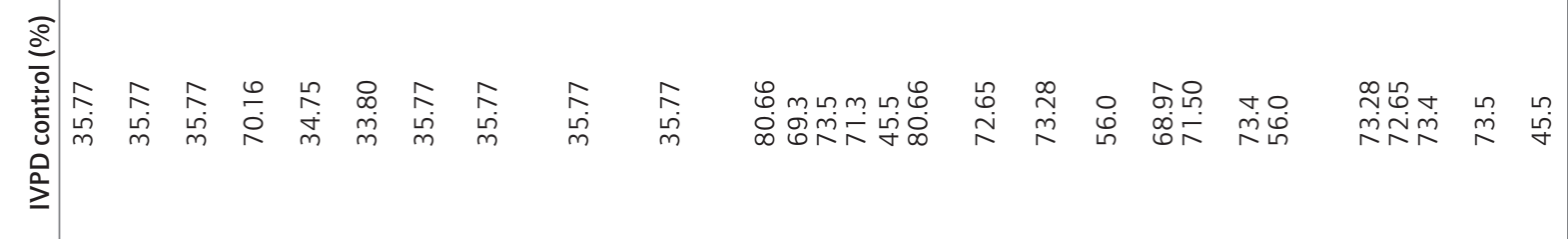

產可

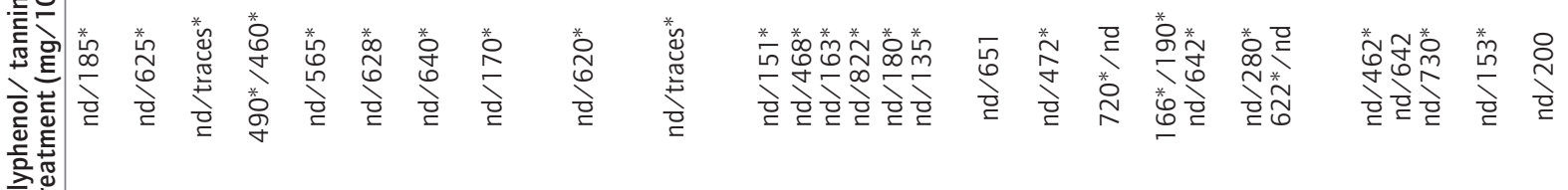

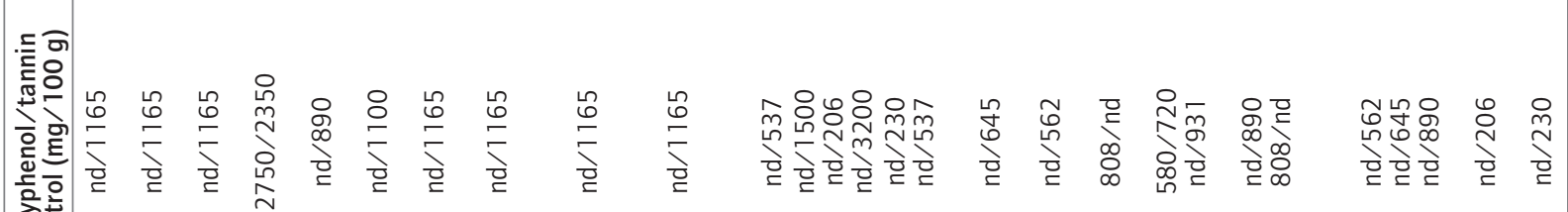
층 竞

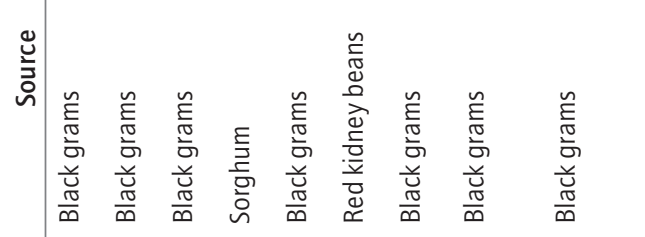

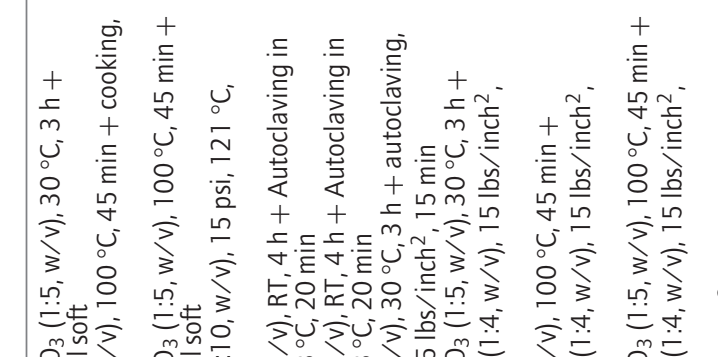

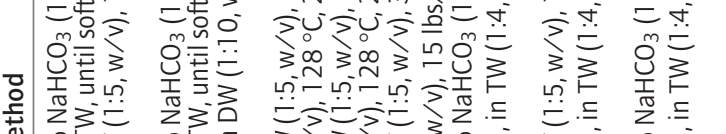

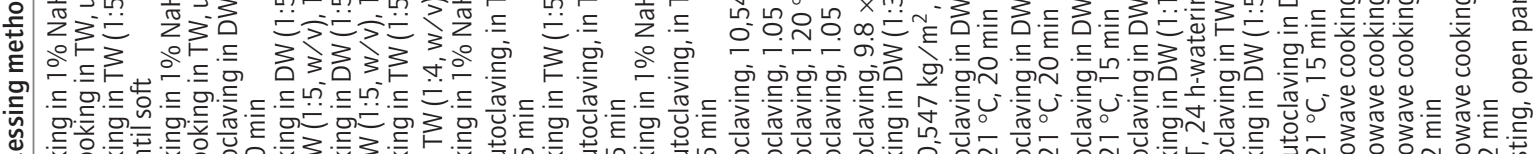

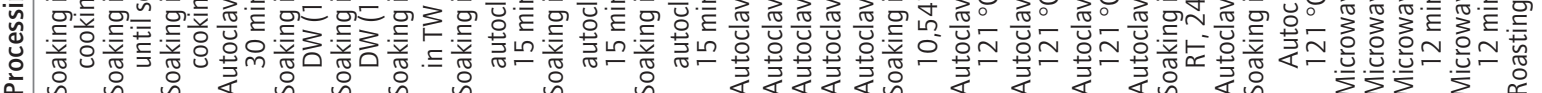




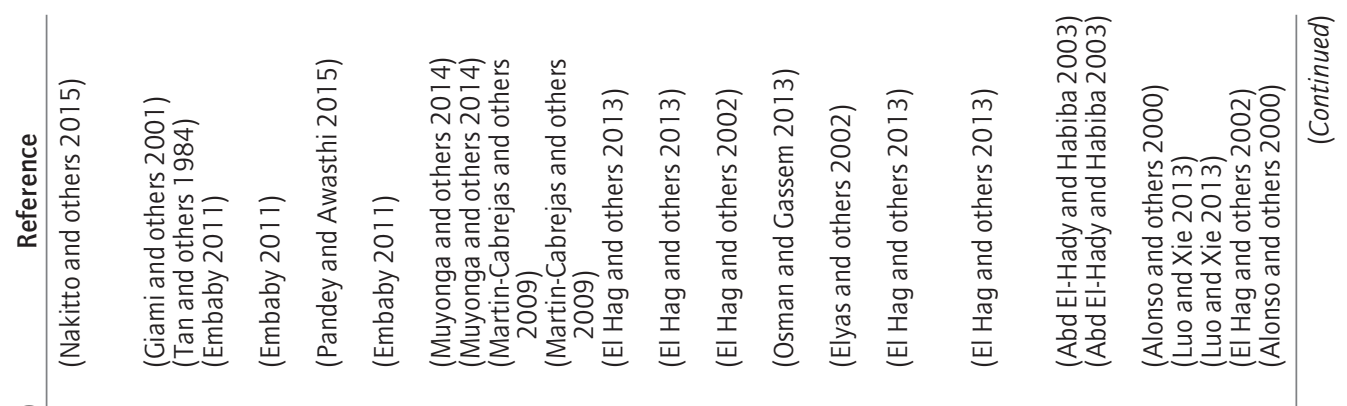

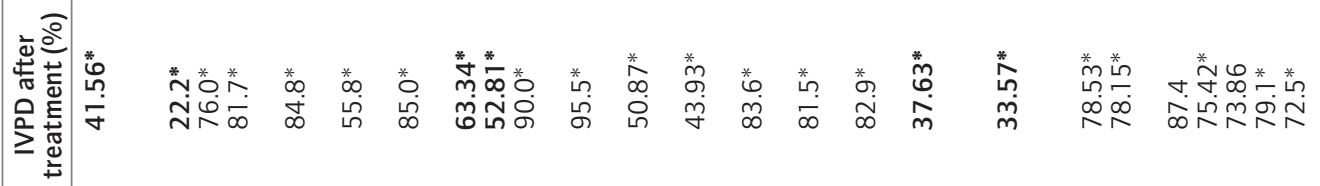

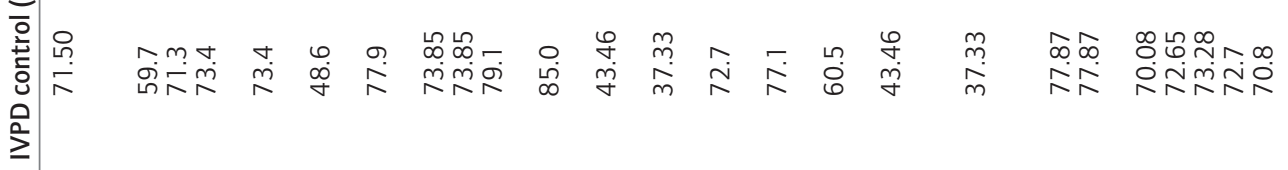

迹政

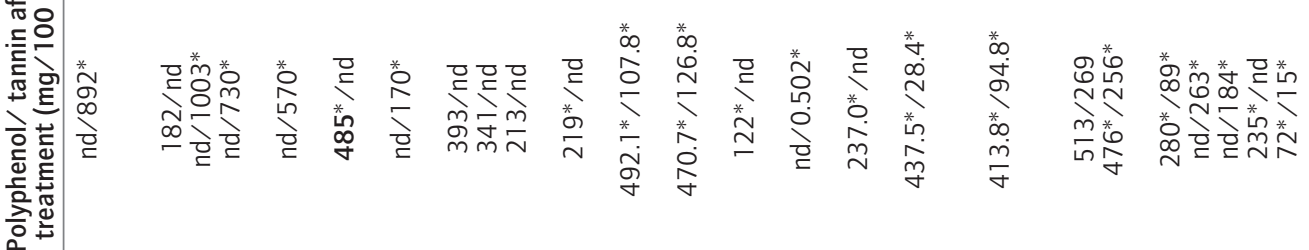

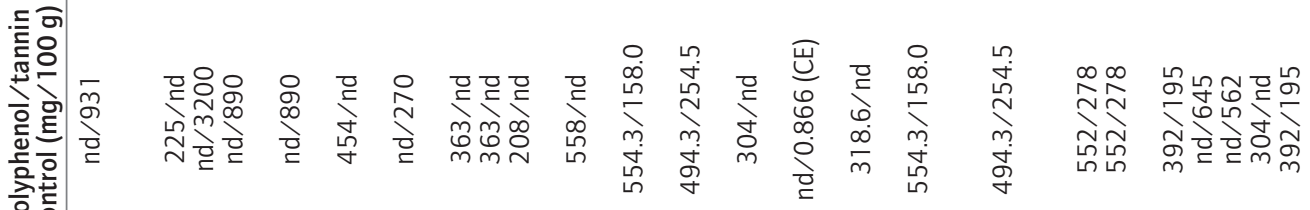
충 훈
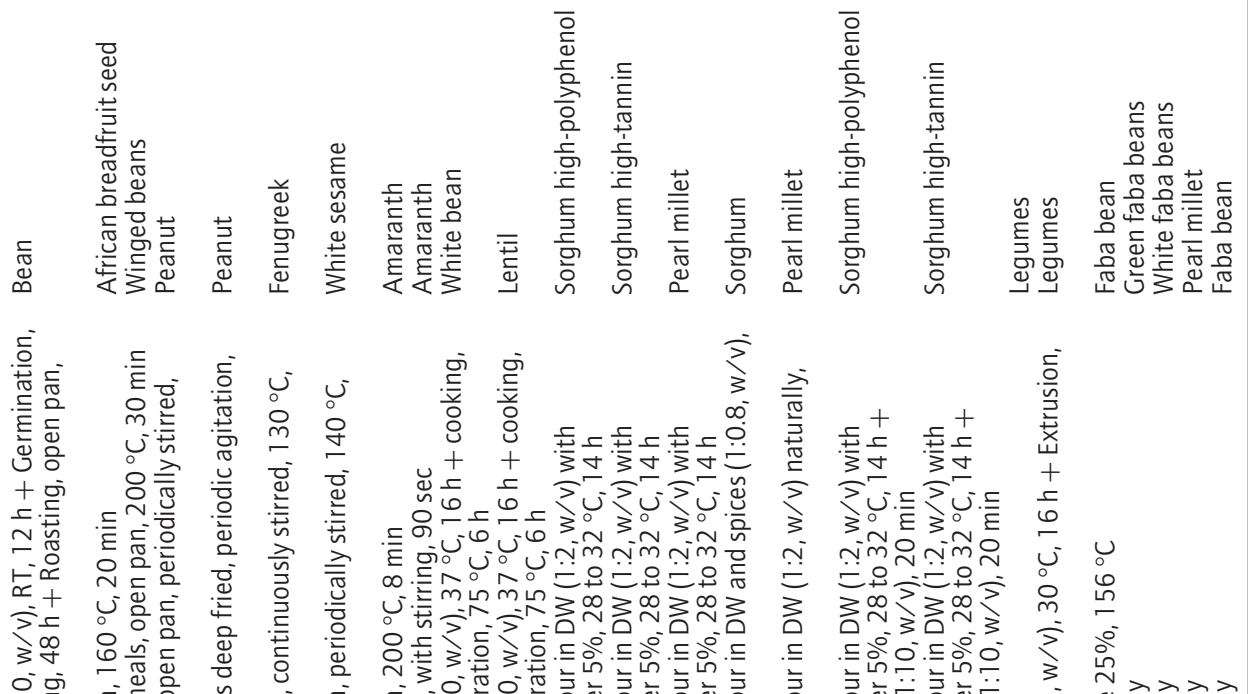

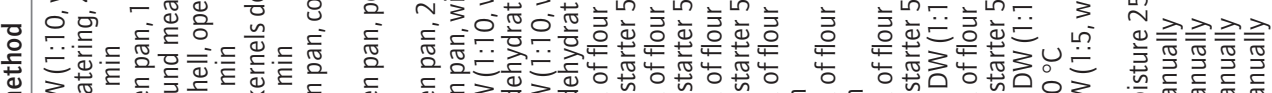

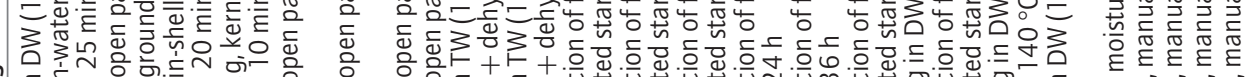
T)

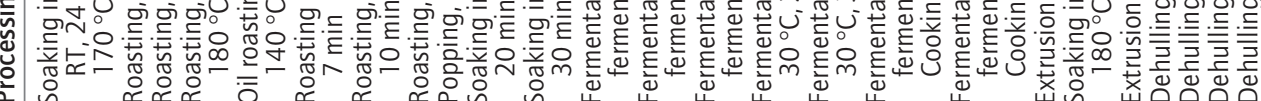




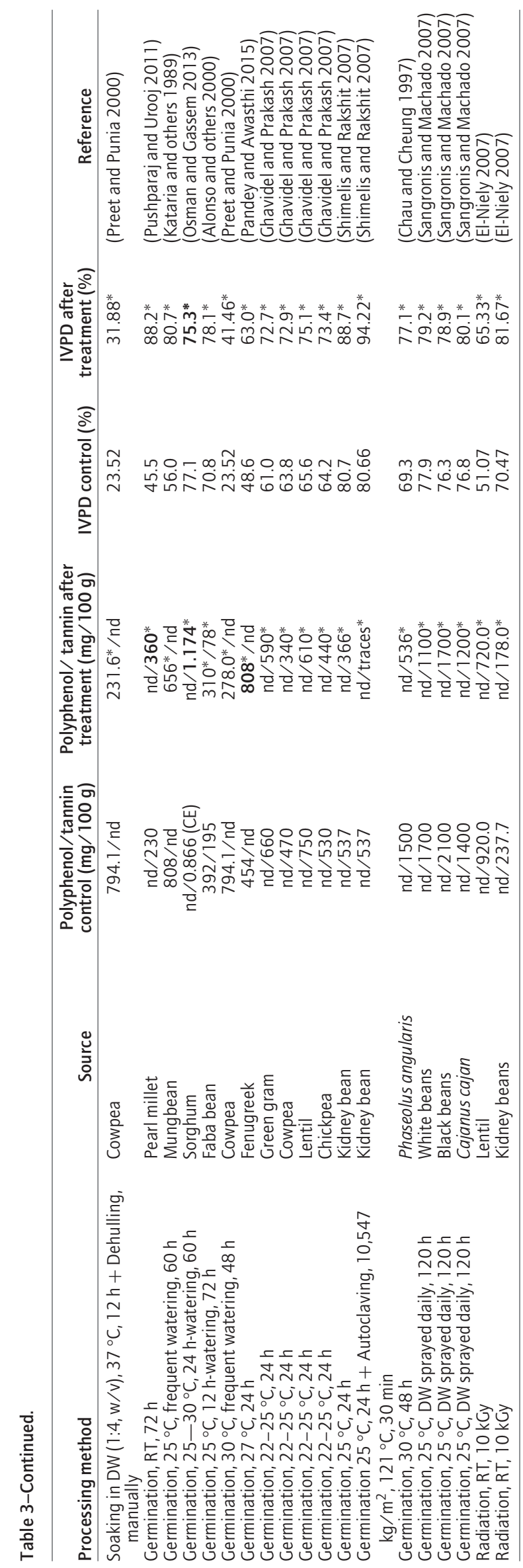


complexes with dietary protein rather than inhibition of enzymes. Processing methods for high-tannin sorghum increase the opportunity for interaction of tannin with dietary protein before it encounters digestive enzymes (Duodu and others 2003). Table 3 shows the effects of different processing methods on polyphenol/tannin content and IVPD.

Soaking in water or alkaline solutions. The high-tannin sorghum varieties form indigestible protein-tannin complexes, which are a major limiting factor in protein utilization. In Uganda, where high-tannin sorghum is grown extensively, there is a unique traditional technology for sorghum processing that involves mixing high-tannin grains with wood-ash slurry, followed by soaking the grains in water overnight. This treatment reduces the tannin content and increases IVPD (Mukuru 1992). In several studies, soaking of the legumes in distilled water was found to decrease polyphenol/tannin content and increase IVPD (Kataria and others 1989; Chau and Cheung 1997; Preet and Punia 2000; Rehman and Shah 2001; Abd El-Hady and Habiba 2003; Shimelis and Rakshit 2007; Luo and Xie 2013; Pandey and Awasthi 2015). In contrast, for sorghum it was shown that only soaking in alkaline solution increases IVPD (Chavan and others 1979; Mukuru 1992; Vijayakumari and others 2007). In addition, soaking of black grams in sodium bicarbonate solution was found to be more efficient for tannin extraction and improvement of IVPD than soaking in boiling water, while soaking in sodium bicarbonate solution have shown to be even better (Rehman and Shah 2001).

Cooking, autoclaving, and roasting. Many studies have reported reduced polyphenol/tannin content with improved IVPD after wet-heat treatments, such as ordinary cooking, microwave cooking, and autoclaving, as well as dry-heat treatments, such as roasting and dehydration (Table 3 and there mentioned references). However, it is interesting that, in several studies, cooking had a negative effect on IVPD, even though polyphenol/tannin content decreased, indicating that tannin content is not the only factor responsible for lowering IVPD (Carbonaro and others 2000; Giami and others 2001; Pushparaj and Urooj 2011; El Hag and others 2013). Low IVPD of cooked seeds may result from changes in proteins themselves during cooking, such as disulfide and nondisulfide crosslinking (Duodu and others 2003). In comparison to ordinary cooking, autoclaving appears to be more effective in improving IVPD of sorghum (Vijayakumari and others 2007), green fava bean seeds (Luo and Xie 2013), black grams and mung beans (Kataria and others 1989), and pearl millet (Pushparaj and Urooj 2011), while soaked cooking was more effective than pressure-cooking the beans (Kataria and others 1989; Shimelis and Rakshit 2007). Also, autoclaving of soaked kidney bean have shown to be better than autoclaving of unsoaked seeds (Shimelis and Rakshit 2007). Roasting has been shown to have a negative effect on IVPD in beans (Nakitto and others 2015), African breadfruit (Giami and others 2001), and amaranth (Muyonga and others 2014). Cooking and autoclaving after soaking in sodium bicarbonate solution almost completely depleted tannins and dramatically increased IVPD in black grams (Rehman and Shah 2001).

Fermentation and malting. Fermentation has been shown to be efficient method to significantly reduce total polyphenol and tannin contents, and to markedly increase IVPD in pearl millet (Elyas and others 2002; El Hag and others 2002; Onyango and others 2013), sorghum flour (El Hag and others 2013; Onyango and others 2013; Osman and Gassem 2013), and beans (Chandra-Hioe and others 2016). The fermentation-induced increase in IVPD is attributed to enzymatic breakdown of complex storage proteins into simpler soluble products during fermentation, as well as a contribution from microflora proteolytic enzymes. Malting is also an efficient processing method for increasing the IVPD of millet and sorghum (Nkama and others 2015). A combination of malting and fermentation resulted in higher digestibility than fermentation alone (Onyango and others 2013), while IVPD was significantly improved after malting of germinated sorghum seeds, which was attributed to indigenous proteases in sprouted seeds (Elkhalil and others 2001). Interestingly, although fermentation alone increased the IVPD of sorghum, fermentation followed by cooking decreased IVPD (El Hag and others 2013).

Dehulling and extrusion. Dehulling has been demonstrated in many studies to be effective in reducing levels of polyphenols and tannins and, consequently, improving IVPD in legumes (Alonso and others 2000; Preet and Punia 2000; El Hag and others 2002; Ghavidel and Prakash 2007; Luo and Xie 2013; Nakitto and others 2015) and finger millet grain (Ramachandra and others 1977). Extrusion has been shown to be an even more efficient processing method for the improvement of IVPD due to the degradation of protein complexes within the extruded samples and the denaturation of protein due to heat and shearing (Alonso and others 2000; Abd El-Hady and Habiba 2003). Decortication and extrusion processing can markedly improve the digestibility of sorghum, as evaluated in comparative balance studies in preschool children (MacLean and others 1983). Despite the increase in antinutritional factor levels other than tannins produced by dehulling, the significantly increased IVPD resulting from this processing method implies an important role for condensed tannins in protein digestion.

Germination. Germination has been found to reduce polyphenol/tannin levels and improve the IVPD of several foods, including pearl millet (Pushparaj and Urooj 2011), sorghum (Elkhalil and others 2001), and legumes (Kataria and others 1989; Chau and Cheung 1997; Alonso and others 2000; Preet and Punia 2000; Ghavidel and Prakash 2007; Sangronis and Machado 2007; Shimelis and Rakshit 2007; Pandey and Awasthi 2015). In addition, autoclaving of germinated seeds have shown to be even more efficient for kidney beans (Shimelis and Rakshit 2007). The improvement in IVPD as a result of germination was attributed to the modification and partial hydrolysis of storage proteins by endogenous proteases produced during germination. In contrast, Osman and Gassem (2013) reported that germination of sorghum varieties significantly increased tannin content, coinciding with a decrease in IVPD.

Irradiation. Interestingly, El-Niely and others (2007) demonstrated that irradiation of different legume seeds, with dose levels up to $10 \mathrm{kGy}$, significantly reduced levels of phytic acid and tannins, enhanced IVPD, and increased the protein efficiency ratio in growing rats in a dose-dependent manner. Therefore, the authors emphasized the use of radiation processing for an improvement in protein digestibility over the benefit of irradiation as a phytosanitary method.

\section{Conclusions and Future Outlook}

Phenolic compounds are part of the composition of many plants and are considered as one of the most important antinutritional factors. Their reversible and irreversible binding to proteins greatly influence protein digestibility and bioavailability of essential amino acids. Several technological treatments have been developed to reduce the phenolic compound contents of plant-based foods and thereby to increase protein digestibility. These technological treatments are especially important for regions of the world where 
nutrition is mainly characterized by the intake of lower-quality ALA plant proteins accompanied by the intake of high amounts of BLG secondary plant metabolites resulting from a predominantly plantfood-based diet. In addition, in developed countries there is an increasing number of people having vegetarian plant-based diet, such as macrobiotic, semi-vegetarian, lacto-ovovegetarian, vegan, and other healthy food-based diet. On the other hand, food fortification with phenolic compounds, as bioactive components, can result in decreased protein digestibility due to their interactions with the food matrix. Therefore, in fortified foods protein digestibility testing should be mandatory, and the benefits provided by phenolic compounds should be balanced with their antinutritional effects.

\section{Acknowledgments}

This work was supported by the Serbian Ministry of Education, Science and Technological Development under Grant No. OI172024.

\section{Conflicts of Interest}

The authors declare no conflict of interest.

\section{Author Contributions}

TCV and DSV researched prior studies, interpreted results, and wrote the manuscript.

\begin{tabular}{|c|c|}
\hline \multicolumn{2}{|c|}{ Nomenclature } \\
\hline $\mathrm{ABR}$ & anthocyanin-enriched black raspberry extract \\
\hline BSA & bovine serum albumin \\
\hline BBTI & Bowman-Birk trypsin inhibitor \\
\hline GTC & catechin-enriched polyphenol extract of green tea \\
\hline $\mathrm{cf}$ & centrifugation \\
\hline $\mathrm{CE}$ & catechin equivalents \\
\hline $\mathrm{CHP}$ & $\begin{array}{l}\text { cross-linked tropomyosin in the presence of caffeic } \\
\text { acid with horseradish peroxidase }\end{array}$ \\
\hline CTC & $\begin{array}{l}\text { cross-linked tropomyosin in the presence of caffeic } \\
\text { acid with tyrosinase }\end{array}$ \\
\hline DW & deionized water \\
\hline DDW & double-deionized water \\
\hline EC & epicatechin \\
\hline ECG & epicatechin-3-gallate \\
\hline EGC & epigallocatechin \\
\hline EGCG & epigallocatechin-3-gallate \\
\hline GAE & gallic acid equivalents \\
\hline GC & gallocatechin \\
\hline GCG & gallocatechin gallate \\
\hline GIT & gastrointestinal tract \\
\hline GSP & grape seed polyphenol extract \\
\hline $\mathrm{Hb}$ & hemoglobin \\
\hline IVPD & in vitro protein digestibility \\
\hline KTI & Kunitz trypsin inhibitor \\
\hline PVP & polyvinylpyrrolidone \\
\hline PDCAAS & protein digestibility-corrected amino acid score \\
\hline RT & room temperature \\
\hline SCE & sour cherry extract \\
\hline SPI & soy protein isolate \\
\hline TA & tannic acid \\
\hline TW & tap water \\
\hline $\mathrm{TP}$ & tea polyphenol \\
\hline ToP & total phenols \\
\hline TCA & trichloroacetic acid \\
\hline
\end{tabular}

\section{$\alpha$-lactalbumin}

$\beta$-lactoglobulin

\section{Supporting Information}

Additional Supporting Information may be found in the online version of this article at the publisher's website:

Table S1. Overview of the studies investigating interactions of phenolic compounds with bovine serum albumin (BSA).

\section{References}

Abd El-Hady EA, Habiba RA. 2003. Efffect of soaking and extrusion conditions on antinutrients and protein digestibility of legume seeds. Lebensm-Wiss Technol 36:285-93.

Alonso R, Aguirre A, Marzo F. 2000. Effects of extrusion and traditional processing methods on antinutrients and in vitro digestibility of protein and starch in faba and kidney beans. Food Chem 68:159-65.

Arimboor R, Arumughan C. 2011. Sea buckthorn (Hippophae rhamnoides) proanthocyanidins inhibit in vitro enzymatic hydrolysis of protein. J Food Sci 76:T130-7.

Bennick A. 2002. Interaction of plant polyphenols with salivary proteins. Crit Rev Oral Biol Med 13:184-96.

Boath AS, Stewart D, McDougall GJ. 2012. Berry components inhibit alpha-glucosidase in vitro: synergies between acarbose and polyphenols from black currant and rowanberry. Food Chem 135:929-36.

Bohin MC, Vincken JP, van der Hijden HTWM, Gruppen H. 2012. Efficacy of food proteins as carriers for flavonoids. J Agric Food Chem 60:4136-43.

Bohn T. 2014. Dietary factors affecting polyphenol bioavailability. Nutr Rev 72:429-52.

Bonfili L, Cecarini V, Amici M, Cuccioloni M, Angeletti M, Keller JN, Eleuteri AM. 2008. Natural polyphenols as proteasome modulators and their role as anti-cancer compounds. FEBS J 275:5512-26.

Bordenave N, Hamaker BR, Ferruzzi MG. 2014. Nature and consequences of non-covalent interactions between flavonoids and macronutrients in foods. Food Funct 5:18-34.

Bras NF, Goncalves R, Mateus N, Fernandes PA, Ramos MJ, Do Freitas V. 2010. Inhibition of pancreatic elastase by polyphenolic compounds. J Agric Food Chem 58:10668-76.

Bravo L, Abia R, Eastwood MA, Saura-Calixto F. 1994. Degradation of polyphenols (catechin and tannic acid) in the rat intestinal tract. Effect on colonic fermentation and faecal output. Br J Nutr 71:933-46.

Budryn G, Nebesny E, Rachwal-Rosiak D, Oracz J. 2013. Fatty acids, essential amino acids, and chlorogenic acids profiles, in vitro protein digestibility and antioxidant activity of food products containing green coffee extract. Intl Food Res J 20:2133-44.

Carbonaro M, Grant G, Cappelloni M, Pusztai A. 2000. Perspectives into factors limiting in vivo digestion of legume proteins: Antinutritional compounds or storage proteins? J Agric Food Chem 48:742-9.

Chandra-Hioe MV, Wong CHM, Arcot J. 2016. The potential use of fermented chickpea and faba bean flour as food ingredients. Plant Food Hum Nutr 71:90-5.

Charlton AJ, Baxter NJ, Khan ML, Moir AJ, Haslam E, Davies AP, Williamson MP. 2002. Polyphenol/peptide binding and precipitation. J Agric Food Chem 50:1593-601.

Chaudhuri S, Chakraborty S, Sengupta PK. 2011. Probing the interactions of hemoglobin with antioxidant flavonoids via fluorescence spectroscopy and molecular modeling studies. Biophys Chem 154:26-34.

Chau CF, Cheung PCK. 1997. Effect of various processing methods on antinutrients and in vitro digestibility of protein and starch of two chinese indigenous legume seeds. J Agric Food Chem 45:4773-6.

Chavan JK, Kadam SS, Ghonsikar CP, Salunkhe DK. 1979. Removal of tannins and improvement of in vitro protein digestibility of sorghum seeds by soaking in alkali. J Food Sci 44:1319-22.

Clifford MN. 2004. Diet-derived phenols in plasma and tissues and their implications for health. Planta Med 70:1103-14

Cui F, Yang K, Li Y. 2015. Investigate the binding of catechins to trypsin using docking and molecular dynamics simulation. PloS One 10:e0125848. Czubinski J, Dwiecki K, Siger A, Kachlicki P, Neunert G, Lampart-Szczapa E, Nogala-Kalucka M. 2012. Release of flavonoids from lupin globulin proteins during digestion in a model system. J Agric Food Chem 60:1830-6. 
Czubinski J, Dwiecki K, Siger A, Neunert G, Lampart-Szczapa E. 2014. Characterisation of different digestion susceptibility of lupin seed globulins. Food Chem 143:418-26.

Czubinski J, Dwiecki K. 2017. A review of methods used for investigation of protein-phenolic compound interactions. Intl J Food Sci Technol 52:573-85.

Dai J, Mumper RJ. 2010. Plant phenolics: Extraction, analysis and their antioxidant and anticancer properties. Molecules 15:7313-52.

Danihelová M, Veverka M, Sturdík E. 2013. Inhibition of pathophysiological proteases with novel quercetin derivatives. Acta Chim Slov 6:115-22.

Davies HS, Pudney PD, Georgiades P, Waigh TA, Hodson NW, Ridley CE, Blanch EW, Thornton DJ. 2014. Reorganisation of the salivary mucin network by dietary components: insights from green tea polyphenols. PloS One 9:e108372.

de Toledo NMV, Rocha LC, da Silva AG, Brazaca SGC. 2013. Interaction and digestibility of phaseolin/polyphenol in the common bean. Food Chem 138:776-80.

Draijer R, Van Dorsten FA, Zebregs YE, Hollebrands B, Peters S, Duchateau GS, Grün CH. 2016. Impact of proteins on the uptake, distribution, and excretion of phenolics in the human body. Nutrients 8(12):814.

Duodu KG, Taylor JRN, Belton PS, Hamaker BR. 2003. Factors affecting sorghum protein digestibility. J Cereal Sci 38:117-31.

Eggum BO, Pedersen B, Jacobsen I. 1983. The influence of dietary tea, coffee and cocoa on protein and energy utilization of soya-bean meal and barley in rats. Br J Nutr 50:197-205.

Ehrnhoefer DE, Bieschke J, Boeddrich A, Herbst M, Masino L, Lurz R, Engemann S, Pastore A, Wanker EE. 2008. EGCG redirects amyloidogenic polypeptides into unstructured, off-pathway oligomers. Nat Struct Mol Biol 15:558-66.

El-Niely HFG. 2007. Effect of radiation processing on antinutrients, in-vitro protein digestibility and protein efficiency ratio bioassay of legume seeds. Radiat Phys Chem 76:1050-7.

El Hag ME, El Tinay AH, Yousif NE. 2002. Effect of fermentation and dehulling on starch, total polyphenols, phytic acid content and in vitro protein digestibility of pearl millet. Food Chem 77:193-6.

El Hag ME, Mohamed Ahmed IA, Suha OA, Eltayeb MM, Babiker EE. 2013. Effect of processing methods on antinutritional factors, protein digestibility and minerals extractability of winter sorghum cultivars. Aust J Basic Appl Sci 7:229-37.

Elkhalil EAI, El Tinay AH, Mohamed BE, Elsheikh EAE. 2001. Effect of malt pretreatment on phytic acid and in vitro protein digestibility of sorghum flour. Food Chem 72:29-32.

Elsheikh EAE, Fadul IA, El Tinay AH. 2000. Effect of cooking on anti-nutritional factors and in vitro protein digestibility (IVPD) of faba bean grown with different nutritional regimes. Food Chem 68:211-2.

Elyas SHA, El Tinay AH, Yousif NE, Elshelkh EAE. 2002. Effect of natural fermentation on nutritive value and in vitro protein digestibility of pearl millet. Food Chem 78:75-9.

Embaby HES. 2011. Effect of heat treatments on certain antinutrients and in vitro protein digestibility of peanut and sesame seeds. Food Sci Technol Res $17: 31-8$

FAO/WHO. 1991. Protein quality evaluation. Report of a Joint FAO/WHO Expert Consultation; Bethesda, Md., USA, 4-8 December 1989. Rome, Italy: Food and Agriculture Organization of the United Nations. Paper No. 51:1-66.

Frazier RA, Deaville ER, Green RJ, Stringano E, Willoughby I, Plant J, Mueller-Harvey I. 2010. Interactions of tea tannins and condensed tannin with proteins. J Pharm Biomed Anal 51:490-5.

Gan J, Chen H, Liu J, Wang Y, Nirasawa S, Cheng Y. 2016. Interactions of beta-conglycinin (7S) with different phenolic acids - impact on structural characteristics and proteolytic degradation of proteins. Intl J Mol Sci 17:1671-84

Georgiades P, Pudney PDA, Rogers S, Thornton DJ, Waigh TA. 2014. Tea Derived Galloylated Polyphenols Cross-Link Purified Gastrointestinal Mucins. PloS One 9:e105302.

Ghavidel RA, Prakash J. 2007. The impact of germination and dehulling on nutrients, antinutrients, in vitro iron and calcium bioavailability and in vitro starch and protein digestibility of some legume seeds. LWT - Food Sci Technol 40:1292-9.

Giami SY, Adindu MN, Hart AD, Denenu EO. 2001. Effect of heat processing on in vitro protein digestibility and some chemical properties of African breadfruit (Treculia africana Decne) seeds. Plant Food Hum Nutr 56:117-26.
Gilani GS, Sepehr E. 2003. Protein digestibility and quality in products containing antinutritional factors are adversely affected by old age in rats. J Nutr 133:220-5.

Goncalves R, Soares S, Mateus N, De Freitas V. 2007. Inhibition of trypsin by condensed tannins and wine. J Agric Food Chem 55:7596-601.

Grussu D, Stewart D, McDougall GJ. 2011. Berry polyphenols inhibit alpha-amylase in vitro: identifying active components in rowanberry and raspberry. J Agric Food Chem 59:2324-31.

Habiba RA. 2002. Changes in anti-nutrients, protein solubility, digestibility, and $\mathrm{HCl}$ extractability of ash and phosphorus in vegetable peas as affected by cooking methods. Food Chem 77:187-92

Hagerman AE, Butler LG. 1981. The specificity of proanthocyanidin-protein interactions. J Biol Chem 256:4494-7.

Halliwell B. 2007. Dietary polyphenols: good, bad, or indifferent for your health? Cardiovasc Res 73:341-7.

Haslam E, Cai Y. 1994. Plant polyphenols (vegetable tannins): gallic acid metabolism. Nat Prod Rep 11:41-66.

Hasni I, Bourassa P, Hamdani S, Samson G, Carpentier R, Tajmir-Riah HA. 2011. Interaction of milk alpha- and beta-caseins with tea polyphenols. Food Chem 126:630-9.

He Q, Lv Y, Yao K. 2007. Effects of tea polyphenols on the activities of alpha-amylase, pepsin, trypsin and lipase. Food Chem 101:1178-82.

Huang HH, Kwok KC, Liang HH. 2004. Effects of tea polyphenols on the activities of soybean trypsin inhibitors and trypsin. J Sci Food Agric 84:121-6.

Huang HH, Zhao MM. 2008. Changes of trypsin in activity and secondary structure induced by complex with trypsin inhibitors and tea polyphenol. Eur Food Res Technol 227:361-5.

Ignat I, Volf I, Popa VI. 2011. A critical review of methods for characterisation of polyphenolic compounds in fruits and vegetables. Food Chem 126:1821-35.

Jansman AJ, Frohlich AA, Marquardt RR. 1994. Production of proline-rich proteins by the parotid glands of rats is enhanced by feeding diets containing tannins from faba beans (Vicia faba L.). J Nutr 124:249-58.

Jia JJ, Gao X, Hao MH, Tang L. 2017. Comparison of binding interaction between beta-lactoglobulin and three common polyphenols using multi-spectroscopy and modeling methods. Food Chem 228:143-51.

Kanakis CD, Hasni I, Bourassa P, Tarantilis PA, Polissiou MG, Tajmir-Riahi HA. 2011. Milk beta-lactoglobulin complexes with tea polyphenols. Food Chem 127:1046-55.

Karaś M, Jakubczyk A, Szymanowska U, Złotek U, Zielińska E. 2017. Digestion and bioavailability of bioactive phytochemicals. Intl J Food Sci Technol 52:291-305.

Kataria A, Chauhan BM, Punia D. 1989. Antinutrients and protein digestibility (in vitro) of mungbean as affected by domestic processing and cooking. Food Chem 32:9-17.

Kay CD, Pereira-Caro G, Ludwig IA, Clifford MN, Crozier A. 2017. Anthocyanins and flavanones are more bioavailable than previously perceived: A review of recent evidence. In: Doyle MP, Klaenhammer TR, editors. Ann Rev Food Sci Technol 8:155-80.

Kroll J, Rawel HM, Seidelmann N. 2000. Physicochemical properties and susceptibility to proteolytic digestion of myoglobin-phenol derivatives. J Agric Food Chem 48:1580-7.

Kroll NG, Rawel HM, Rohn S. 2003. Reactions of plant phenolics with food proteins and enzymes under special consideration of covalent bonds. Food Sci Technol Res 9:205-18

Kuhnert N, Dairpoosh F, Jaiswal R, Matei M, Deshpande S, Golon A, Nour H, Karakose H, Hourani N. 2011. Hill coefficients of dietary polyphenolic enzyme inhibitiors: can beneficial health effects of dietary polyphenols be explained by allosteric enzyme denaturing? J Chem Biol 4:109-16.

Lamothe S, Azimy N, Bazinet L, Couillard C, Britten M. 2014. Interaction of green tea polyphenols with dairy matrices in a simulated gastrointestinal environment. Food Funct 5:2621-31.

Li SA, Huang KL, Zhong M, Guo J, Wang WZ, Zhu RH. 2010. Comparative studies on the interaction of caffeic acid, chlorogenic acid and ferulic acid with bovine serum albumin. Spectrochim Acta Mol Biomol Spectrosc 77:680-6.

Li Q, Wei QY, Yuan ED, Yang JG, Ning ZX. 2014. Interaction between four flavonoids and trypsin: effect on the characteristics of trypsin and antioxidant activity of flavonoids. Int J Food Sci Tech 49:1063-9.

Liu GY, Hu MJ, Sun LC, Han XY, Liu QM, Alcocer M, Fei DX, Cao MJ, Liu GM. 2017. Allergenicity and oral tolerance of enzymatic cross-linked 
tropomyosin evaluated using cell and mouse models. J Agric Food Chem 65:2205-13

Lochocka K, Bajerska J, Glapa A, Fidler-Witon E, Nowak JK, Szczapa T, Grebowiec P, Lisowska A, Walkowiak J. 2015. Green tea extract decreases starch digestion and absorption from a test meal in humans: a randomized, placebo-controlled crossover study. Sci Rep 5:12015-9.

Łoś J, Podsedek A 2001. Tannins from different foodstuffs as trypsin inhibitors. Polish J Food Nutr Sci 13/54:51-5.

Luo YW, Xie WH. 2013. Effect of different processing methods on certain antinutritional factors and protein digestibility in green and white faba bean (Vicia faba L.). Cyta-J Food 11:43-9.

Ma J, Yin YM, Liu HL, Xie MX. 2011. Interactions of flavonoids with biomacromolecules. Curr Org Chem 15:2627-40.

MacLean WC, Jr., Lopez de Romana G, Gastanaduy A, Graham GG. 1983. The effect of decortication and extrusion on the digestibility of sorghum by preschool children. J Nutr 113:2071-7.

Manach C, Williamson G, Morand C, Scalbert A, Rémésy C. 2005. Bioavailability and bioefficacy of polyphenols in humans. I. Review of 97 bioavailability studies. Am J Clin Nutr 81:230S-42S.

Marín L, Miguélez EM, Villar CJ, Lombó F. 2015. Bioavailability of dietary polyphenols and gut microbiota metabolism: antimicrobial properties. BioMed Res Intl 2015:1-18.

Marques TR, Caetano AA, Simao AA, Castro FCD, Ramos VD, Correa AD. 2016. Methanolic extract of Malpighia emarginata bagasse: phenolic compounds and inhibitory potential on digestive enzymes. Rev Bras Farmacogn 26:191-6.

Martin-Cabrejas MA, Aguilera Y, Pedrosa MM, Cuadrado C, Hernandez T, Diaz S, Esteban RM. 2009. The impact of dehydration process on antinutrients and protein digestibility of some legume flours. Food Chem 114:1063-8.

Martinez-Gonzalez AI, Diaz-Sanchez AG, de la Rosa LA, Vargas-Requena CL, Bustos-Jaimes I, Alvarez-Parrilla E. 2017. Polyphenolic compounds and digestive enzymes: in vitro non-covalent interactions. Molecules 22: 669-92

Mehansho H, Hagerman A, Clements S, Butler L, Rogler J, Carlson DM. 1983. Modulation of proline-rich protein biosynthesis in rat parotid glands by sorghums with high tannin levels. Proc Natl Acad Sci USA 80:3948-52. Millward DJ, Layman DK, Tome D, Schaafsma G. 2008. Protein quality assessment: impact of expanding understanding of protein and amino acid needs for optimal health. Am J Clin Nutr 87:1576s-81s.

Mole S, Waterman PG. 1987. Tannic acid and proteolytic enzymes: Enzyme inhibition or substrate deprivation? Phytochemistry 26:99-102.

Mukuru SZ. 1992. Traditional processing of high-tannin sorghum grain in Uganda its effect on tannin, protein digestibility, and rat growth. J Agric Food Chem 40:1172-5.

Muyonga JH, Andabati B, Ssepuuya G. 2014. Effect of heat processing on selected grain amaranth physicochemical properties. Food Sci Nutr 2:9-16. Nakitto AM, Muyonga JH, Nakimbugwe D. 2015. Effects of combined traditional processing methods on the nutritional quality of beans. Food Sci Nutr 3:233-41.

Naz S, Siddiqi R, Dew TP, Williamson G. 2011. Epigallocatechin-3-gallate inhibits lactase but is alleviated by salivary proline-rich proteins. J Agric Food Chem 59:2734-8.

Nergiz C, Gokgoz E. 2007. Effects of traditional cooking methods on some antinutrients and in vitro protein digestibility of dry bean varieties (Phaseolus vulgaris L.) grown in Turkey. Intl J Food Sci Technol 42:868-73.

Nkama I, Gbenyi DI, Hamaker BR. 2015. Effects of malting and roasting of millet and sorghum on protein digestibility, mineral availability, soluble sugar composition and consumer acceptability of Dakuwa. Ind J Nutr 2:112-8.

Nour AAM, Ahmed IAM, Babiker EE, Ahmed WAM. 2015. Effect of supplementation and cooking on in vitro protein digestibility and anti-nutrients of pearl millet flour. Am J Food Sci Health 1:69-75.

Onyango CA, Ochanda SO, Mwasaru MA, Ochieng JK, Mathooko FM, Kinyuru JN. 2013. Effects of malting and fermentation on anti-nutrient reduction and protein digestibility of red sorghum, white sorghum and pearl millet. J Food Res 2:41-9.

Osman MA, Gassem M. 2013. Effects of domestic processing on trypsin inhibitor, phytic, acid, tannins and in-vitro protein digestibility of three sorghum varieties. J Agric Technol 9:1187-98.

Pandey KB, Rizvi SI. 2009. Plant polyphenols as dietary antioxidants in human health and disease. Oxid Med Cell Longev 2:270-8.
Pandey H, Awasthi P. 2015. Effect of processing techniques on nutritional composition and antioxidant activity of fenugreek (Trigonella foenum-graecum) seed flour. J Food Sci Technol Mys 52:1054-60.

Papadopoulou A, Frazier RA. 2004. Characterization of protein-polyphenol interactions. Trends Food Sci Technol 15:186-90.

Petzke KJ, Schuppe S, Rohn S, Rawel HM, Kroll J. 2005. Chlorogenic acid moderately decreases the quality of whey proteins in rats. J Agric Food Chem 53:3714-20.

Plundrich NJ, Kulis M, White BL, Grace MH, Guo R, Burks AW, Davis JP, Lila MA. 2014. Novel strategy to create hypoallergenic peanut protein-polyphenol edible matrices for oral immunotherapy. J Agric Food Chem 62:7010-21.

Preet K, Punia D. 2000. Antinutrients and digestibility (in vitro) of soaked, dehulled and germinated cowpeas. Nutr Health 14:109-17.

Pushparaj FS, Urooj A. 2011. Influence of processing on dietary fiber, tannin and in vitro protein digestibility of pearl millet. Food Nutr Sci 2:895900.

Quideau S, Deffieux D, Douat-Casassus C, Pouységu L. 2011. Plant polyphenols: chemical properties, biological activities, and synthesis. Angew Chem Intl Ed 50:586-621.

Radosavljevic J, Nordlund E, Mihajlovic L, Krstic M, Bohn T, Buchert J, Velickovic TC, Smit J. 2014. Sensitizing potential of enzymatically cross-linked peanut proteins in a mouse model of peanut allergy. Mol Nutr Food Res 58:635-46.

Ramachandra G, Virupaksha TK, Shadaksharaswamy M. 1977. Relationship between tannin levels and in vitro protein digestibility in finger millet (Eleusine coracana Gaertn.). J Agric Food Chem 25:1101-4.

Rawel HM, Kroll J, Riese B. 2000. Reactions of chlorogenic acid with lysozyme: Physicochemical characterization and proteolytic digestion of the derivatives. J Food Sci 65:1091-8.

Rawel HM, Kroll J, Hohl UC. 2001. Model studies on reactions of plant phenols with whey proteins. Nahrung 45:72-81.

Rawel HM, Rohn S, Kruse HP, Kroll J. 2002a. Structural changes induced in bovine serum albumin by covalent attachment of chlorogenic acid. Food Chem 78:443-55.

Rawel HM, Czajka D, Rohn S, Kroll J. 2002b. Interactions of different phenolic acids and flavonoids with soy proteins. Intl J Biol Macromol 30:137-50.

Rawel HA, Rohn S, Kroll J. 2003. Influence of a sugar moiety (rhamnosylglucoside) at 3-O position on the reactivity of quercetin with whey proteins. Intl J Biol Macromol 32:109-20.

Rehman Z, Shah WH. 2001. Tannin contents and protein digestibility of black grams (Vigna mungo) after soaking and cooking. Plant Foods Hum Nutr 56:265-73.

Rehman ZU, Shah WH. 2005. Thermal heat processing effects on antinutrients, protein and starch digestibility of food legumes. Food Chem 91:327-31.

Renard CMGC, Watrelot AA, Le Bourvellec C. 2017. Interactions between polyphenols and polysaccharides: mechanisms and consequences in food processing and digestion. Trend Food Sci Technol 60:43-51.

Rohn S, Rawel HM, Kroll J. 2002. Inhibitory effects of plant phenols on the activity of selected enzymes. J Agric Food Chem 50:3566-71.

Rohn S, Rawel HM, Wollenberger U, Kroll J. 2003. Enzyme activity of alpha-chymotrypsin after derivatization with phenolic compounds. Nahrung 47:325-9.

Rohn S, Petzke KJ, Rawel HM, Kroll J. 2006. Reactions of chlorogenic acid and quercetin with a soy protein isolate - Influence on the in vivo food protein quality in rats. Mol Nutr Food Res 50:696-704.

Sakulnarmrat K, Srzednicki G, Konczak I. 2014. Composition and inhibitory activities towards digestive enzymes of polyphenolic-rich fractions of Davidson's plum and quandong. LWT - Food Sci Technol 57:366-75.

Samuels TL, Pearson ACS, Wells CW, Stoner GD, Johnston N. 2013. Curcumin and anthocyanin inhibit pepsin-mediated cell damage and carcinogenic changes in airway epithelial cells. Ann Oto Rhinol Laryn 122:632-41.

Sangronis E, Machado CJ. 2007. Influence of germination on the nutritional quality of Phaseolus vulgaris and Cajanus cajan. LWT - Food Sci Technol 40:116-20

Shimelis EA, Rakshit SK. 2007. Effect of processing on antinutrients and in vitro protein digestibility of kidney bean (Phaseolus vulgaris L.) varieties grown in East Africa. Food Chem 103:161-72. 
Selinheimo E, Autio K, Kruus K, Buchert J. 2007. Elucidating the mechanism of laccase and tyrosinase in wheat bread making. J Agric Food Chem 55:6357-65.

Shahidi F, Ambigaipalan P. 2015. Phenolics and polyphenolics in foods, beverages and spices: antioxidant activity and health effects-a review. J Funct Foods 18:820-97.

Shahkhalili Y, Finot PA, Hurrell R, Fern E. 1990. Effects of foods rich in polyphenols on nitrogen excretion in rats. J Nutr 120:346-52.

Shahwar D, Raza MA, Shafiq-Ur-Rehman, Abbasi MA, Atta-Ur-Rahman. 2012. An investigation of phenolic compounds from plant sources as trypsin inhibitors. Nat Prod Res 26:1087-93.

Siebert KJ, Troukhanova NV, Lynn PY. 1996. Nature of polyphenol-protein interactions. J Agric Food Chem 44:80-5.

Skrabanja V, Laerke HN, Kreft I. 2000. Protein-polyphenol interactions and in vivo digestibility of buckwheat groat proteins. Pflug Arch Eur J Phy 440:R129-31.

Stanic D, Monogioudi E, Dilek E, Radosavljevic J, Atanaskovic-Markovic M, Vuckovic O, Raija L, Mattinen M, Buchert J, Cirkovic Velickovic T. 2010. Digestibility and allergenicity assessment of enzymatically crosslinked beta-casein. Mol Nutr Food Res 54:1273-84.

Stojadinovic M, Radosavljevic J, Ognjenovic J, Vesic J, Prodic I, Stanic-Vucinic D, Cirkovic Velickovic T. 2013. Binding affinity between dietary polyphenols and beta-lactoglobulin negatively correlates with the protein susceptibility to digestion and total antioxidant activity of complexes formed. Food Chem 136:1263-71.

Stojadinovic M, Pieters R, Smit J, Cirkovic Velickovic T. 2014. Cross-linking of beta-lactoglobulin enhances allergic sensitization through changes in cellular uptake and processing. Toxicol Sci 140:224-35.

Swieca M, Gawlik-Dziki U, Dziki D, Baraniak B, Czyz J. 2013. The influence of protein-flavonoid interactions on protein digestibility in vitro and the antioxidant quality of breads enriched with onion skin. Food Chem 141:451-8.

Swieca M, Seczyk L, Gawlik-Dziki U, Dziki D. 2014. Bread enriched with quinoa leaves - the influence of protein-phenolics interactions on the nutritional and antioxidant quality. Food Chem 162:54-62.

Seczyk L, Swieca M, Gawlik-Dziki U. 2015. Nutritional and health-promoting properties of bean paste fortified with onion skin in the light of phenolic-food matrix interactions. Food Funct 6:3560-6.

Tagliazucchi D, Verzelloni E, Conte A. 2005. Effect of some phenolic compounds and beverages on pepsin activity during simulated gastric digestion. J Agric Food Chem 53:8706-13.

Tan NH, Wong KC, Lumen BO. 1984. Protein digestibilities of raw and heat-treated winged bean (Psophocarpus tetragonolobus). J Agric Food Chem 32:819-22.

Tantoush Z, Stanic D, Stojadinovic M, Ognjenovic J, Mihajlovic L, Atanaskovic-Markovic M, Cirkovic Velickovic T. 2011a. Digestibility and allergenicity of beta-lactoglobulin following laccase-mediated cross-linking in the presence of sour cherry phenolics. Food Chem 125:84-91.

Tantoush Z, Mihajlovic L, Kravic B, Ognjenovic J, Jankov RM, Cirkovic Velickovic T, Stanic-Vucinic D. 2011b. Digestibility of beta-lactoglobulin following cross-linking by Trametes versicolor laccase and apple polyphenols. J Serb Chem Soc 76:847-55.
Tantoush Z, Apostolovic D, Kravic B, Prodic I, Mihajlovic L, Stanic-Vucinic D, Cirkovic Velickovic T. 2012. Green tea catechins of food, supplements facilitate pepsin digestion of major food allergens, but hampers their digestion if oxidized by phenol oxidase. J Funct Foods 4:650-60.

Taylor J, Bean SR, Ioerger BP, Taylor JRN. 2007. Preferential binding of sorghum tannins with gamma-kafirin and the influence of tannin binding on kafirin digestibility and biodegradation. J Cereal Sci 46:22-31.

Thring TSA, Hili P, Naughton DP. 2009. Anti-collagenase, anti-elastase and anti-oxidant activities of extracts from 21 plants. BMC Complement Altern Med 9:27.

Tsao R. 2010. Chemistry and biochemistry of dietary polyphenols. Nutrients 2:1231-46.

Venkatachalam M, Sathe SK. 2003. Phaseolin in vitro pepsin digestibility: role of acids and phenolic compounds. J Agric Food Chem 51:3466-72.

Vijayakumari K, Pugalenthi M, Vadivel V. 2007. Effect of soaking and hydrothermal processing methods on the levels of antinutrients and in vitro protein digestibility of Bauhinia purpurea L. seeds. Food Chem 103:968-75.

Xiao HZ, Liu BG, Mo HZ, Liang GZ. 2015. Comparative evaluation of tannic acid inhibiting alpha-glucosidase and trypsin. Food Res Intl 76:605-10.

Wang S, Moustaid-Moussa N, Chen L, Mo H, Shastri A, Su R, Bapat P, Kwun I, Shen CL. 2014. Novel insights of dietary polyphenols and obesity. J Nutr Biochem 25:1-18

Wittenauer J, Mackle S, Sussmann D, Schweiggert-Weisz U, Carle R. 2015. Inhibitory effects of polyphenols from grape pomace extract on collagenase and elastase activity. Fitoterapia 101:179-87.

Wroblewski K, Muhandiram R, Chakrabartty A, Bennick A. 2001. The molecular interaction of human salivary histatins with polyphenolic compounds. Eur J Biochem 268:4384-97.

Wu XL, He WY, Wang WP, Luo XP, Cao HY, Lin LX, Feng KQ, Liu ZG. 2013. Investigation of the interaction between (-)-epigallocatechin-3-gallate with trypsin and alpha-chymotrypsin. Intl J Food Sci Technol 48:2340-7.

Yang H, Landis-Piwowar K, Chan TH, Dou QP. 2011. Green tea polyphenols as proteasome inhibitors: implication in chemoprevention. Curr Cancer Drug Tar 11:296-306.

Yenrina R, Permata DA, Rasjmida D, Tayandi R. 2016. In vitro protein digestibility and physical properties of instant teh talua dried by spray dryer. Intl J Adv Sci Engg Inf Technol 6:84-7.

Yu J, Mi Y, Ji S. 2016. In vitro evaluating the influence of grape seed polyphenol extract on the digestibility of macronutrients. J Health Sci 4:167-76.

Zdunczyk Z, Frejnagel S, Wroblewska M, Juskiewicz J, Oszmianski J, Estrella I. 2002. Biological activity of polyphenol extracts from different plant sources. Food Res Intl 35:183-6.

Zee BM, Garcia BA. 2012. Discovery of lysine post-translational modifications through mass spectrometric detection. Essays Biochem 52:147-63

Zeng HJ, Yang R, Liang HL, Qu LB. 2015. Molecular interactions of flavonoids to pepsin: insights from spectroscopic and molecular docking studies. Spectrochim Acta A 151:576-90. 